OPEN ACCESS

Edited by:

Sophia N. Wassermann, University of California, Davis,

United States

Reviewed by:

Edison D. Macusi,

Institute of Agriculture and Life

Sciences (IALS), Davao Oriental State

College of Science and Technology

(DOSCST), Philippines

Philippa Cohen,

WorldFish (Malaysia), Malaysia

*Correspondence:

Farisal U. Bagsit

fubagsit@up.edu.ph

${ }^{t}$ These authors have contributed equally to this work

Specialty section:

This article was submitted to Marine Affairs and Policy,

a section of the journal

Frontiers in Marine Science

Received: 12 December 2020

Accepted: 02 June 2021

Published: 29 June 2021

Citation:

Bagsit FU, Frimpong E, Asch RG and Monteclaro HM (2021) Effect of

a Seasonal Fishery Closure on

Sardine and Mackerel Catch

in the Visayan Sea, Philippines.

Front. Mar. Sci. 8:640772.

doi: 10.3389/fmars.2021.640772

\section{Effect of a Seasonal Fishery Closure on Sardine and Mackerel Catch in the Visayan Sea, Philippines}

\author{
Farisal U. Bagsit ${ }^{1,2 * t}$, Eugene Frimpong ${ }^{3 t}$, Rebecca G. Asch ${ }^{4 t}$ and \\ Harold M. Monteclaro ${ }^{5 t}$ \\ ${ }^{1}$ Institute of Fisheries Policy and Development Studies, College of Fisheries and Ocean Sciences, University of the \\ Philippines Visayas, Iloilo, Philippines, ${ }^{2}$ Department of Coastal Studies, Thomas Harriot College of Arts and Sciences, East \\ Carolina University, Greenville, NC, United States, ${ }^{3}$ Department of Coastal Studies, Thomas Harriot College of Arts \\ and Sciences, East Carolina University, Greenville, NC, United States, ${ }^{4}$ Department of Biology, Thomas Harriot College \\ of Arts and Sciences, East Carolina University, Greenville, NC, United States, ${ }^{5}$ Institute of Marine Fisheries and Oceanology, \\ College of Fisheries and Ocean Sciences, University of the Philippines Visayas, Iloilo, Philippines
}

The implementation of seasonal fishery closures (SFC) can be controversial due to the frequent lack of clear objectives, monitoring and empirical evidence of management success. In the Philippines, an SFC implemented for the conservation of important fishery commodities in the Visayan Sea has been ruled a success after stricter implementation of this fishery policy in 2012. However, a comprehensive, detailed, and robust analysis of this fishery policy is lacking. Using a difference-in-differences (DID) framework, we estimated the effect of SFC on the interannual and seasonal catch for sardine and mackerel. We expanded our analysis to other species not regulated under the SFC policy. We also conducted semi-structured interviews ( $N=235)$, focus group discussions $(N=9)$ and key informant interviews $(N=37)$ involving municipal fisheries stakeholders in the surrounding municipalities around the Visayan Sea, and representatives from the government and non-government agencies, to complement our analyses. Seasonal analyses of catch data show a significant increase in sardine catch at the end of the seasonal closure among SFC-participating provinces. However, overall, the SFC had no significant effect on sardine interannual catch among the provinces participating in the SFC. We also found no significant effect of the SFC on interannual and seasonal catch for mackerel. Furthermore, our findings show no significant changes in fishing pressure to other aquatic species. Interview results corroborate our DID findings for mackerel, but not for sardine. The varying perceptions on the outcomes of the SFC policy can be attributed to several challenges such as lack of implementing guidelines, lack of alternative livelihoods for the affected stakeholders, persistence of illegal fishing, and uneven implementation of the SFC. Since the management objective of this SFC was to conserve the regulated species, alternative management measures may be needed to achieve this goal. This could entail more consistent enforcement, improved cooperation and communication between fisheries managers and stakeholders, fish size or gear restrictions, and identification and conservation of key habitats needed to restore overexploited species.

Keywords: seasonal fishery closure, fishery policy evaluation, fisheries management, Visayan Sea, sardine, mackerel 


\section{INTRODUCTION}

Seasonal fishery closures (SFCs) are areas temporarily closed to fishing for one or more species or to specific fishing gears (Gell and Roberts, 2002). Various justifications have been offered for closing fisheries for limited or longer periods. For example, SFCs have been widely used in fisheries management to prevent overfishing and collapse of a fishery, rebuild depleted stocks, reduce gear conflicts, and reduce bycatch of protected species (National Oceanic and Atmospheric Administration (NOAA), 1985; Gell and Roberts, 2002; Farmer et al., 2016; Agar et al., 2019). In some cases, SFCs are imposed during the breeding or spawning period of species with the aim to reduce fishing mortality directly, thus, achieving greater annual reproductive output (Murawski et al., 2000; Arendse et al., 2007). According to Beets and Manuel (2007), SFCs are management strategies that are easily enforced and often accepted by fishers due to their simplicity. In most instances, there are few theoretical justifications for seasonal closures (Gulland, as cited by Beets and Manuel, 2007). Despite potential benefits from SFCs, there are varying reviews about this management strategy in places where it has been implemented (Arendse et al., 2007; Jiang et al., 2009; Mendoça and Sobrinho, 2013; Wang et al., 2015). For example, SFCs implemented in the Gulf of Mexico shrimp fishery and Florida lobster fishery [National Oceanic and Atmospheric Administration (NOAA), 1985; Beets and Manuel, 2007], United States Virgin Islands grouper fishery (Beets and Friedlander, 1999) and coral reefs in Kenya (McClanahan, 2010) showed positive results. In contrast, seasonal closure enacted for the groundfish fishery in New England had little impact on reviving the groundfish stocks (Sinclair and Valdimarsson, 2003; Brodziak et al., 2004). In the case of the Pacific halibut fishery, while initial attempts for a closed season provided the base for subsequent regulatory measures, it failed to curb fishing effort and was thought to have limited conservation value (Babcock et al., 1931; Bell, 1969; Skud, 1985). In a paper that reviewed the temporal and seasonal closures used in fisheries management in tropical and subtropical regions, and important species for Hawaii, Beets and Manuel (2007) noted that, although quantitative analyses of the specific value of this fishery management strategy have not been conducted, managers who evaluated SFCs concluded that they have been useful and beneficial based on perceived benefits and stock effects (Beets and Manuel, 2007).

The implementation of spawning area closures in particular, can be controversial among some communities due to the frequent lack of clear objectives, monitoring and empirical evidence of management success (Sadovy and Domeier, 2005; Beets and Manuel, 2007; Grüss et al., 2014b; Clarke et al., 2015; Rola et al., 2018). For a spawning closure to have a net benefit to population growth, there should be a reduction in the annual fishing mortality at the scale of the stock (Clarke et al., 2015). However, a spawning closure may have no effect if the spawning fishes are not particularly susceptible to capture during spawning or there is a change in the fishing effort during other seasons (Beets and Manuel, 2007; Grüss et al., 2014a; Grüss and Robinson, 2015). For example, fishers may respond with greater fishing effort during open season to compensate for their inactivity during the closed season. Further, Everson (1986) argues that fishing bans during spawning seasons may not have an effect on future stocks because even if the enormous number of eggs that are produced by an individual fish can help in building up a stock, additional catching capacity will likely be introduced in the fishery, and unless the open season is shortened, fishing mortality may ultimately tend to return to its original level. There is also a high rate of natural mortality among early life history stages of fish as small fishes are normally exposed to more potential predation than bigger fishes and escape ability typically increases with body size (Bailey and Houde, 1989; Stige et al., 2019). Furthermore, fishing effort may be diverted to other resources that may be overfished or nearing an overfished condition (Beets and Manuel, 2007) or, to other areas (Horwood, 2000).

Seasonal fishery closures are particularly common in data poor fisheries because they can be implemented in areas where stock assessments have not been conducted to assess allowable catch. For example, the winter closure for Pacific Halibut was introduced before the existence of the International Pacific Halibut Commission (IPHC) and conservation was only a minor consideration in its implementation [Thompson and Freeman, 1930; International Fisheries Commission (IFC), 1948; Skud, 1985]. Biological justifications for the closed season were noted only in later years, but the IPHC retained it based on economic considerations (Babcock et al., 1931; Skud, 1985). Agar et al. (2019) note that seasonal closures have been advanced for protecting aggregating fisheries for which managers have limited information on the location and timing of their reproductive events. In the case of the Philippines, the introduction of the SFC in its fisheries was anchored on precautionary principle in response to observed decline in fish catch. The Philippines first implemented a SFC in 1939 to conserve sardines, herrings, and mackerels in the Visayan Sea, as per Fish and Game Administrative Order (FGAO) No. 13, s. 1939 [Department of Agriculture-Bureau of Fisheries and Aquatic Resources (DABFAR), 1939]. However, there is no information whether this regulation considered the species biology and its corresponding socioeconomic impact in decision making. The declaration of the SFC in 1939 was one of the first initiatives of the Philippine government to conserve the country's aquatic resources by regulating fishing activities in its critical fishing grounds (Ronquillo and Llana, 1987). It has undergone several revisions. The most recent issuance related to the SFC is the Fisheries Administrative Order No. 167-3, s. 2013, which shortens the SFC period to 3 months (November 15 to February 15; DA-BFAR, 2013a). This change was prompted by the realization on the part of the Bureau of Fisheries and Aquatic Resources (BFAR), the lead agency in the management of the fisheries and aquatic resources in the Philippines, that poor compliance of fishers with the SFC was caused by the longer period (Bagsit, 2020).

Studies that assessed the fisheries in the Visayan Sea have indicated heavy exploitation of stocks, particularly the pelagic species (Dalzell and Ganaden, 1987; Dalzell et al., 1990; Armada, 1999; Guanco et al., 2009; Bayate and Mesa, 2012). This was confirmed by Armada (1999) who noted that the maximum sustainable yield for most of the small pelagic species in the Visayan Sea was already reached in the mid-1970s. Sardine and mackerel are among the commercially important small pelagic 
fishes that historically dominated the Philippine fishery (Dalzell and Ganaden, 1987; Dalzell et al., 1990). Analysis of fish catch composition of different gears designed to catch pelagic and demersal species in the Visayan Sea shows that sardine (Sardinella fimbriata and S. lemuru) and mackerel (Rastrelliger kanagurta and $R$. brachysoma) were the most frequently caught fishes (Armada, 1999). Guanco et al. (2009) also observed that 67\% of the catch from commercial fishing vessels (e.g., Danish seine, purse seine, trawl, and ring net) were predominantly pelagic fishes, with sardine and mackerel dominating the catch. These species are among the highest biomass of catches in terms of volume (DA-BFAR, 2014). They rank first in catch among marine municipal fisheries and third in commercial fisheries production (Subong, 2017). Municipal fisheries in the Philippines involve small-scale, labor-intensive fishing operations using motorized or non-motorized boats of three gross tons (GT) or less, within municipal waters (from the coastline to $15 \mathrm{~km}$ seaward). In contrast, the commercial fisheries sector is composed of capitalintensive corporate enterprises with more centralized fishing operations that take place beyond the $15 \mathrm{~km}$ boundary of the municipal waters up to the seaward edge of the 200-nautical mile Exclusive Economic Zone (EEZ) [Republic Act (RA) 8550, 1998]. These boats are classified into small-scale (3.1 GT up to $20 \mathrm{GT}$ ); medium-scale (20.1 GT up to $150 \mathrm{GT}$ ); and large-scale (>150 GT). Overall, fish catch from the Visayan Sea comprises approximately $10-13 \%$ of the total production of sardine and mackerel in the country (DA-BFAR, 2012).

Despite the SFC being in effect for eight decades, it was not strictly enforced until 2012. This coincided with the change in the BFAR's leadership which revitalized the Bureau's efforts in addressing destructive fishing methods, the continuous intrusion of commercial fishers in the municipal waters, and conservation efforts in fisheries (DA-BFAR, 2011). This resulted in the review, amendment, and active implementation of the SFCs. Since the start of a reinvigorated enforcement, there had been claims that the SFC was a success, noting an increase in fish catch each year at the end of the seasonal closure period (DA-BFAR, 2013b; Mesa, 2014; Ramos, 2014). However, in a recent study which examined whether the implementation of the SFC in the Visayan Sea has achieved its conservation goals, results showed a decrease in the catch-per-unit-effort (CPUE) of municipal fishers whose target species are sardine (Napata et al., 2020). Nonetheless, their analyses were limited to sardine only and not mackerel, hence, did not include all the species covered by the SFC. Further, the CPUE data presented were based on perceptions of municipal fishers using encircling gillnets only. As a result, there are contradicting indicators regarding management success of the Visayan Sea SFC and a comprehensive, detailed, and robust analysis inclusive of multiple species is yet to be performed. To address this issue, we applied a difference-indifferences (DID) approach to examine the effect of the SFC policy on the (1) municipal and commercial interannual catch for sardine and mackerel among provinces participating in the SFC in the Visayan Sea; (2) municipal and commercial seasonal catch for sardine and mackerel (i.e., catch during closed vs open seasons) among SFC-participating provinces; (3) interannual catch for the non-target species not regulated under the SFC; and (4) we conducted semi-structured interviews (SSI), focus group discussions (FGDs) and key informant interviews (KIIs) to complement our DID results. The interannual and seasonal analyses are complementary because they addressed different hypotheses. The interannual analysis addressed whether the strict implementation of the SFC led to increased catches of the protected species in recent years. In contrast, the seasonal analysis evaluated the claim of the BFAR that the SFC is effective because catches rebound seasonally after the end of the SFC. The third analysis examined whether there was a shift in fishing pressure to other species that are not regulated under the SFC. The SSIs, FGDs, and KIIs provided in-depth insights on the results of our DID analyses which helped us better understand the SFC in the context of the stakeholders involved in its implementation. Different insights into fisheries can be provided by fisheries dependent catch data versus qualitative interviews, as these datasets can sometimes illustrate differences between perceptions versus reality. Understanding stakeholder's perceptions of the SFC policy is vital in the sustainable management of the Visayan Sea.

The findings in this paper are important at multiple scales. At the local scale, people's livelihoods are at stake due to the disruption in their livelihoods during the SFC. At the national scale, the government has scarce resources to implement fishery policy, thus it is important to understand which policies are likely to be the most effective and which require review and revision. Our approach might also be useful to replicate in other regions with data poor fisheries and no stock assessments. At the global scale, global maxima of marine biodiversity is noted in the Indo-Malay-Philippines archipelago and data shows peak marine biodiversity in the central Philippines where the Visayan Sea lies (Carpenter and Springer, 2005). Philippine sardine biodiversity, for example, is among the highest in the world (Willette et al., 2011). Hence, appropriate management of the Visayan Sea is critical for maintaining biodiversity. Proper management of key biodiversity areas is integral in achieving the United Nation's Sustainable Development Goal 14 on conservation and sustainable use of the oceans and marine resources for sustainable development. This is especially true given that recent data show that the sustainability of global fishery resources continues to decline and current efforts to protect key marine environments and small scale fishers, among others, fell short of addressing the urgent need to protect these vast and fragile resources (United Nations, 2020). Finally, the Philippines is one of the major fish producing countries in the world in terms of marine capture production, hence, the sustainability of its fishing grounds is critical to local and global food security and protection of livelihood of coastal dwellers (FAO, 2020).

\section{MATERIALS AND METHODS}

\section{Study Area and Data}

The Visayan Sea is a traditional and major fishing ground in the Philippines (Food and Agriculture Organization (FAO), 2000; Ferrer, 2009). It is in the central Philippines and covers an area of about $10,000 \mathrm{~km}^{2}$ (Figure 1). It is surrounded by three regions 
(V-Bicol region, VI-Western Visayas and VII-Central Visayas) and 31 coastal municipalities in five provinces: Capiz, Iloilo, Negros Occidental, Cebu, and Masbate. This body of water is relatively shallow, with water depths of approximately 40 meters (Armada, 1999).

Provincial-level longitudinal fish catch data were obtained from the Philippine Statistics Authority [PSA] $(2018)^{1}$ to inform our analysis. The provincial-level data were aggregates of the municipal-level data, which are not publicly available. The data were comprised of sardine and mackerel catch from municipal and commercial fishers of the Visayan Sea. The PSA collected fish catch data on a quarterly basis using a Quarterly Municipal Fisheries Survey (QMFS) from traditional landing centers in 67 provinces. Five key informants in each center provided information on the average daily volume (in metric tons or $\mathrm{MT})$ of unloading and price per kilogram $(\mathrm{PhP} / \mathrm{kg})$ of the top 31 species and other fishes combined in an "others" category. Additional data were gathered by the PSA from non-traditional landing centers that are managed by the Philippine Fisheries Development Authority (PFDA) and local government units (LGUs) [Philippine Statistics Authority (PSA), 2016].

Specifically, we considered Bali sardine (S. lemuru), Fimbriated sardine (S. fimbriata), Indian mackerel ( $R$. kanagurta), and Indo-Pacific mackerel ( $R$. brachysoma) spanning the period 2007-2018. Strict enforcement of the SFC happened in 2012. Hence, we analyzed fish catch data 6 years before and 6 years after 2012. Herrings were not included in the analysis because present landings of this species in the Visayan Sea are considered negligible. For example, in 2019 data from the PSA indicated that herring landings in the study sites comprised only $0.6 \%$ among the 33 fish species reported. Similarly, Guanco et al. (2009) and Armada (1999) showed that herring landings in the Visayan Sea were not substantial.

We analyzed data from provinces enforcing the SFC (participating group) and those not enforcing the SFC (nonparticipating group) (Supplementary Table 1). Since the enclosed area around the SFC in the Visayan Sea is surrounded by the provinces of Capiz, Iloilo, Negros Occidental, Cebu and Masbate, these areas were assigned as the participating group. We included all other provinces in the Philippines that have reported catch for sardine and mackerel for at least 7 years of the inclusive period (2007-2018) as the non-participating group. All other provinces wherein an SFC for similar species has been implemented were excluded from the non-participating group. Overall, 61 provinces were analyzed for municipal sardine catch, 46 provinces for commercial sardine catch, 61 provinces for municipal mackerel catch and 47 provinces for commercial mackerel catch. A summary of the sample size in each category of this analysis for sardine and mackerel is provided in Supplementary Tables 2, 3.

Data were aggregated at the provincial level but not all municipalities in these provinces observed the SFC. We argue, however, that province-level data should not have confounding effects on our results as previous studies show high concentration of fish catch for sardine and mackerel in the Visayan Sea

${ }^{1}$ http://openstat.psa.gov.ph/ and the enclosed area during SFC is composed largely of municipal waters of the SFC-participating municipalities in the surrounding provinces around Visayan Sea. Hence, we assumed that immediate provinces surrounding the Visayan Sea form our participating group. Further, we assumed that sardine and mackerel fisheries are homogeneous throughout the Philippines.

\section{Empirical Framework and Estimation}

We adopted a DID framework to examine the effect of the SFC policy on sardine and mackerel catch. The DID framework is a variation of the before-after-control-impact (BACI) design analysis (Smith, 2002). The framework is one of the most popular tools used in applied research to evaluate the effect of policy interventions on independent variables. DID and BACI analyses have been widely used in ecology to evaluate natural- and humaninduced perturbations on ecological systems when treatment sites cannot be randomly chosen (Conner et al., 2016). More specifically, it has been used to assess the effects of fishing area closures (Claudet and Guidetti, 2010; Ojeda-Martinez et al., 2011; Osenberg et al., 2011; Fenberg et al., 2012; Cheung et al., 2015; Clarke et al., 2015). To use DID, we needed observed outcomes of the group that received the intervention, in this case, the SFC (i.e., the treatment or the participating group) and a group that is not exposed to the intervention (i.e., the control or the non-participating group). Information on both groups is required before and after the intervention. This allowed for the comparison of the potential outcomes of the intervention to outcomes without the intervention. The conventional DID framework assumes that, in the absence of the intervention, the average effect on the participating and non-participating groups would have followed a similar path over time, implying similar characteristics. However, this strict assumption may not be plausible if attributes that are thought to be associated with the dynamics of the independent variable are unbalanced between the participating and non-participating group (Abadie, 2005), which is typical for quasi-experiments like ours.

The first DID model examined the effect of the SFC policy on interannual catch for sardine and mackerel. That is,

$$
Y_{i t}=\alpha+\beta_{1} P_{i t}+\beta_{2} G_{i t}+\beta_{3}(P \times G)_{i t}+\varepsilon_{i t},
$$

where $Y$ is the observed catch, $P$ is a dummy variable representing the policy-year, and is equal to one if year is after 2012 and zero otherwise); $G$ is a dummy variable that is equal to one if the SFC is enforced in the province and zero otherwise; $i$ is province; and $t$ is year; $\alpha$ and $\beta$ are parameters; and $\varepsilon_{i t}$ is the random error term which is assumed to be normally distributed. The parameter of greatest interest is $\beta_{3}$, which estimates the average effect of the SFC on observed catch among participating provinces.

The second specification (equation 2) examined the effect of the SFC policy on seasonal catch for sardine and mackerel:

$$
\begin{aligned}
& Y_{i t}=\gamma+\delta_{1} P_{i t}+\delta_{2} S_{i t}+\delta_{3} G_{i t}+\delta_{4}(P \times S)_{i t} \\
& +\delta_{5}(P \times G)_{i t}+\delta_{6}(S \times G)_{i t}+\delta_{7}(P \times S \times G)_{i t}+\varepsilon_{i t .}
\end{aligned}
$$

Except for $\delta$ and $S$, the terms in equation 2 are as defined in equation 1. $S$ is a dummy variable which is equal to one if SFC is 


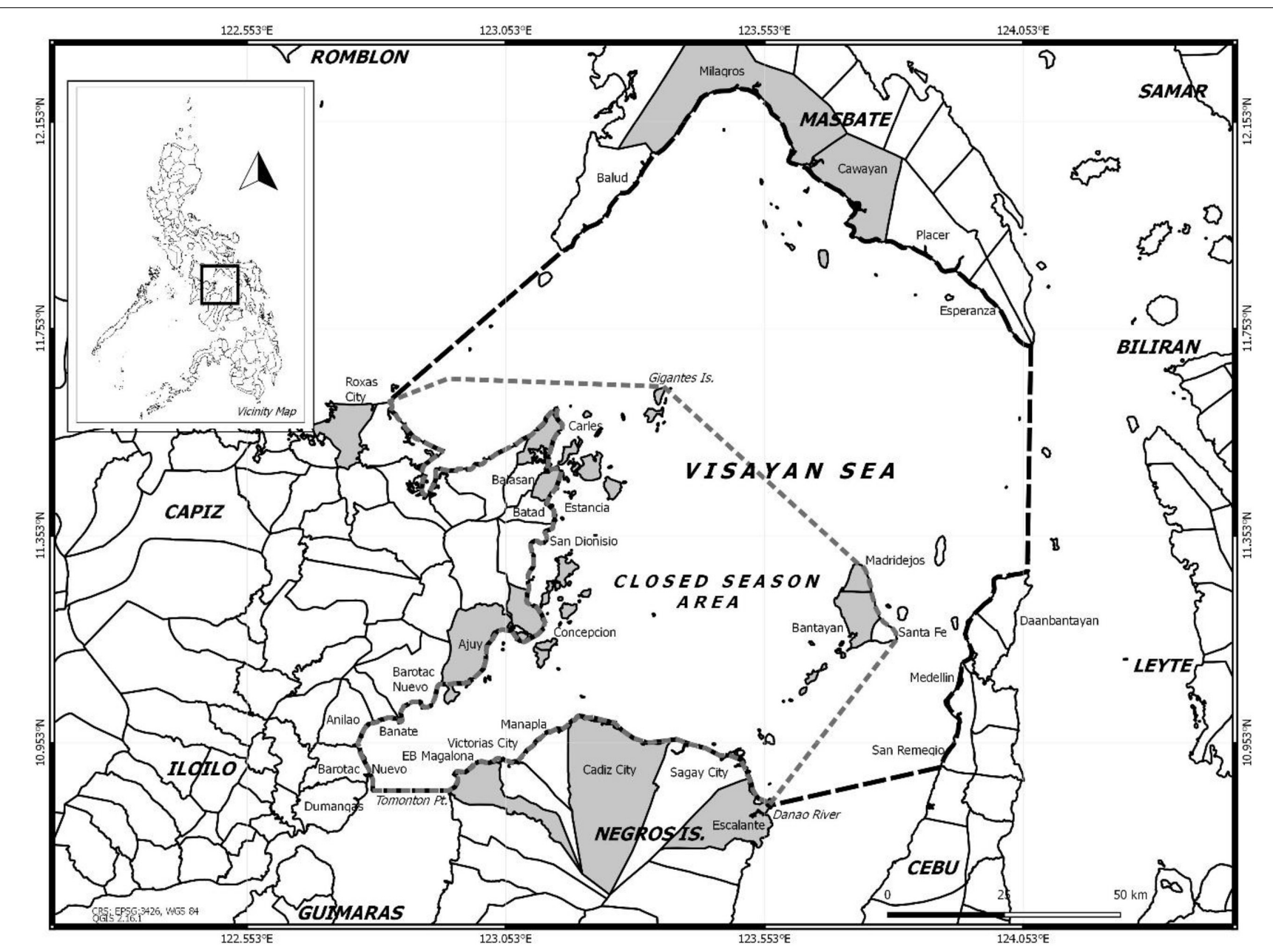

FIGURE 1 | Map showing the study sites (gray shade) and the seasonal fishery closure area (gray broken lines) in the Visayan Sea, Philippines. The black dash lines indicate the boundary of the Visayan Sea.

not enforced in a season and zero otherwise, and $\delta$ are parameters. The parameter $\delta_{7}$ indicates the average effect of the SFC on the observed seasonal catch. Since this is a three-way interaction term, this effect would vary as a function of $\mathrm{P}$ (policy-year).

Equations 1 and 2 were estimated using Generalized Estimating Equations (GEE) (Liang and Zeger, 1986). GEE estimated the population average effects, took into account the covariance structure of the errors, and used a robust sandwich estimator for the standard errors. The GEE was also robust to the misspecification of the correlation structure (Rokicki et al., 2018). That is, it allowed for obtaining coefficient estimates when analyzing correlated data without relying on a joint distribution of the responses, which is usually unknown (Wilson and Lorenz, 2015). Further, it used quasi-likelihood estimation rather than maximum likelihood estimation (MLE) or ordinary least squares (OLS), which are more sensitive to variance structure specification [Pennsylvania State University (PSU), 2018]. We specified the link function as identity and the covariance matrix as exchangeable. The GEE estimation routine in Stata version 13.1 was used in this study. As a robustness check, we also estimated the models using panel fixedeffects and presented the results side-by-side with that of the GEE (Supplementary Tables 5, 6). While the panel fixed-effects allowed for the unobserved province effects to correlate with the independent variables, it did not allow for the estimation of time-invariant variables. In all models, standard errors were clustered at the province level to allow for arbitrary serial correlation of observations within provinces. Results from the GEE and panel fixed effects, as they relate to the parameter of greatest interests, were similar, thus, we chose to discuss the GEE results.

A third set of DID analyses were performed using GEE to examine whether SFC implementation might affect non-target species not regulated under the SFC. This effect could occur if fishers more heavily targeted alternative species during the SFC. This analysis was conducted at the interannual scale and used the same set of participating and non-participating provinces as described above. Provincial-level longitudinal fish catch data available at the PSA portal was used for the analysis of the other 27 fishes. A list of these species is provided in the Supplementary 
Materials (Supplementary Table 4). PSA provides fish catch data for 31 species; four of these are the regulated species analyzed as previously described (sardine and mackerel). We expanded our analysis to include the other 27 species.

\section{Semi-Structured Interviews, Focus Group Discussions, and Key Informant Interviews}

To investigate whether fisher perceptions of the SFC strict implementation match or diverge from the picture painted by analysis of catch statistics, we conducted a face-to-face SSI among 235 municipal fisheries stakeholders of the Visayan Sea to complement our DID results. Nine of the 18 municipalities that were initially included in the Visayan Sea SFC were randomly selected to represent study sites. These included four municipalities in the province of Iloilo (Carles, Estancia, Concepcion, and Ajuy), three municipalities in the province of Negros Occidental (Cadiz City, E.B. Magalona, and Escalante City), and two municipalities in the province of Cebu (Bantayan and Madridejos). Two municipalities in the province of Masbate (Milagros and Cawayan) and one city in the province of Capiz (Roxas City) were added to ensure representativeness of the municipalities in the five provinces surrounding the Visayan Sea considering that previous studies on Visayan Sea were limited in geographical scope. For example, the study by Ferrer (2009) focused on municipalities in Northern Iloilo only, while the study by Napata et al. (2020) included municipalities in the provinces of Iloilo, Negros Occidental, Cebu and Capiz, but failed to include municipalities in Masbate. The additional municipalities were selected based on geographical location, accessibility, and safety considerations.

A non-probability, purposive sampling strategy was used to select the interview respondents (Bernard, 2017), which included municipal fishers, fish dryers, fish vendors/fish traders/fish brokers, LGU representatives, fish wardens, and members of the Philippine National Police-Maritime Group and Philippine Coast Guard (PNP-MG/PCG). We focused on municipal fisheries stakeholders in the fishing communities surrounding the Visayan Sea primarily because the enclosed area during the SFC is largely comprised of municipal waters $(\sim 75 \%)$. Table 1 shows the number of respondents interviewed per group.

A SSI questionnaire was prepared initially in English, then translated to the local dialects since the populations in the study sites speak different dialects. In the provinces of Iloilo and Negros Occidental, the primary spoken language is Hiligaynon, while in the province of Cebu, people speak Cebuano/Bisaya. In contrast, populations in the province of Masbate predominantly speak Minasbate that has mutual intelligibility with Hiligaynon. Cebuano/Bisaya is also spoken in the southeastern part of Masbate. The SSI questionnaire was pre-tested in one of the study sites, municipality of Ajuy, Iloilo, to ensure that the instrument was comprehensive and that questions were clear and easy to understand. Field interviews were conducted from February to April 2019.

Results of these interviews are described in depth in Bagsit (2020). We present here only the questions and results that are
TABLE 1 | Summary of respondents for the SSIs, FGDs, and KIls conducted.

\begin{tabular}{|c|c|c|c|}
\hline Respondents & SSI $(N=235)$ & $\mathrm{FGD}^{*}(N=9)$ & $\mathrm{KII}(N=37)$ \\
\hline Municipal fisher & 117 & & \\
\hline Fish dryer & 35 & & \\
\hline $\begin{array}{l}\text { Fish vendor/Fish trader/Fish } \\
\text { broker }\end{array}$ & 35 & & \\
\hline Local government unit & 27 & & \\
\hline Fish warden & 10 & & \\
\hline $\begin{array}{l}\text { Philippine National } \\
\text { Police-Maritime Group/ } \\
\text { Philippine Coast Guard }\end{array}$ & 11 & & \\
\hline Government agency & - & - & 7 \\
\hline Non-government agency & - & - & 5 \\
\hline $\begin{array}{l}\text { City/Municipal Fisheries and } \\
\text { Aquatic Resource Management } \\
\text { Council }\end{array}$ & - & - & 25 \\
\hline Total & 235 & 9 & 37 \\
\hline
\end{tabular}

*The FGDs were participated in by different set of municipal fishery stakeholders $(N=77)$ from the study sites.

relevant to the objective to understand how the SFC has affected fishery catch for sardine and mackerel. Specifically, we asked the respondents to specify their level of agreement with the following statements: (1) There is an observed increase in the sardine catch in the last 5 years; and (2) There is an observed increase in the mackerel catch in the last 5 years. Responses were measured using a Likert scale (e.g., a score of 5 means the respondent strongly agrees with the statement, while a score 1 indicates strong disagreement with the statement). Respondents' motivations in following the SFC and their coping mechanisms during the time the SFC is in effect were also explored and are documented in Bagsit (2020).

In addition, nine FGDs that were participated in by 77 municipal fisheries stakeholders and KIIs with representatives from government and non-government organizations $(N=12)$ and members of the City or Municipal Fisheries and Aquatic Resource Management Councils (C/MFARMCs) in the study sites $(N=25)$ were conducted to complement results from the SSI (Table 1). FGD and KII participants were asked about their opinions whether the SFC is achieving its purpose and about issues and challenges in the implementation of the SFC in the Visayan Sea. This complemented the SSI and catch data analysis by providing local insights from managers and non-government agencies involved in fisheries management and conservation in the country, about underlying issues related to documented catch trends and stakeholder's perception of those trends.

\section{RESULTS}

\section{Interannual DID Analysis of Sardine and Mackerel Catch}

Results from the interannual DID model showed a significantly greater volume of sardine catch throughout all years among SFC-participating provinces as indicated by the estimated 


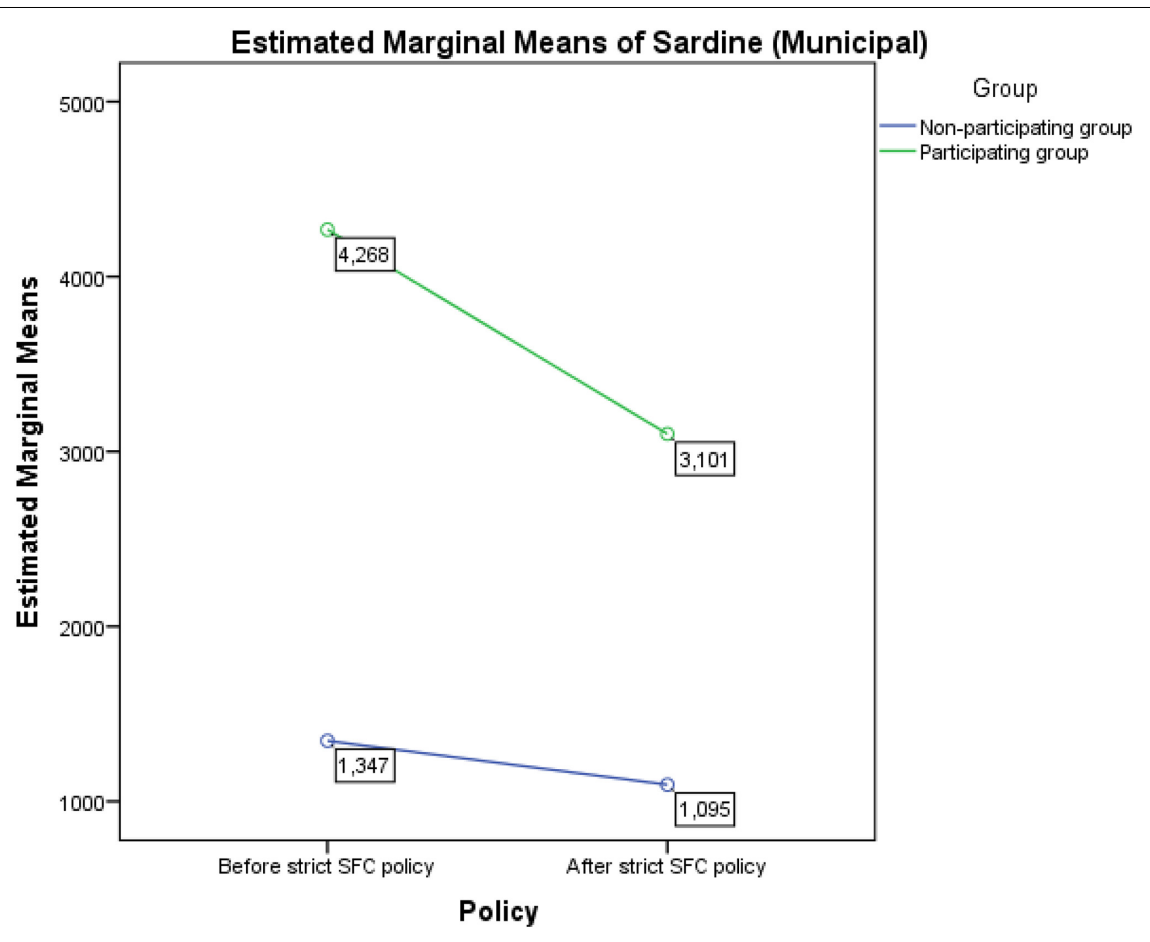

FIGURE 2 | Estimated marginal means of municipal catch for sardine (in MT) between the non-participating and participating groups, before and after the strict implementation of the SFC policy in the Visayan Sea.

coefficient on the participating group (G). Specifically, we found that sardine catch is 2,922 MT higher in municipal sector and 2,993 MT higher in commercial sector, among provinces observing the SFC compared to their counterparts. The estimated parameter on policy-year $(\mathrm{P})$ indicated that sardine catch had declined by 251 MT in the municipal sector and $178 \mathrm{MT}$ in the commercial sector since the strict implementation of the SFC. This decline was common to both participating and non-participating groups. More importantly, the coefficient of the interaction term $G \times P$ indicated that compared to non-SFC-participating provinces, sardine catch for municipal and commercial sectors among SFC-participating provinces declined by 917 MT and 1,133 MT, respectively, since the strict implementation of SFC in 2012 (Supplementary Table 5). This suggested a much greater decline in annual catches among participating groups compared to non-participating groups, even though both groups experienced declining sardine catch (Figures 2, 3).

Difference-in-differences results on interannual changes in catch showed a significantly higher municipal and commercial mackerel catch among SFC-participating provinces (G) compared to the non-participating provinces both before and after the strict enforcement (Figures 4, 5). Further, the estimated parameter on policy-year (P) indicated that mackerel catch had significantly decreased by 273 MT in the municipal sector and $316 \mathrm{MT}$ in the commercial sector, following the strict enforcement of the SFC. The estimated coefficients on the interaction term $\mathrm{G} \times \mathrm{P}$ indicated an increase in municipal mackerel catch by $561 \mathrm{MT}$ and a decline in commercial mackerel catch by 99 MT, but they were not significant (Supplementary Table 5). This suggests that there was no significant change in mackerel catch among participating group in both sectors following the strict implementation of the SFC.

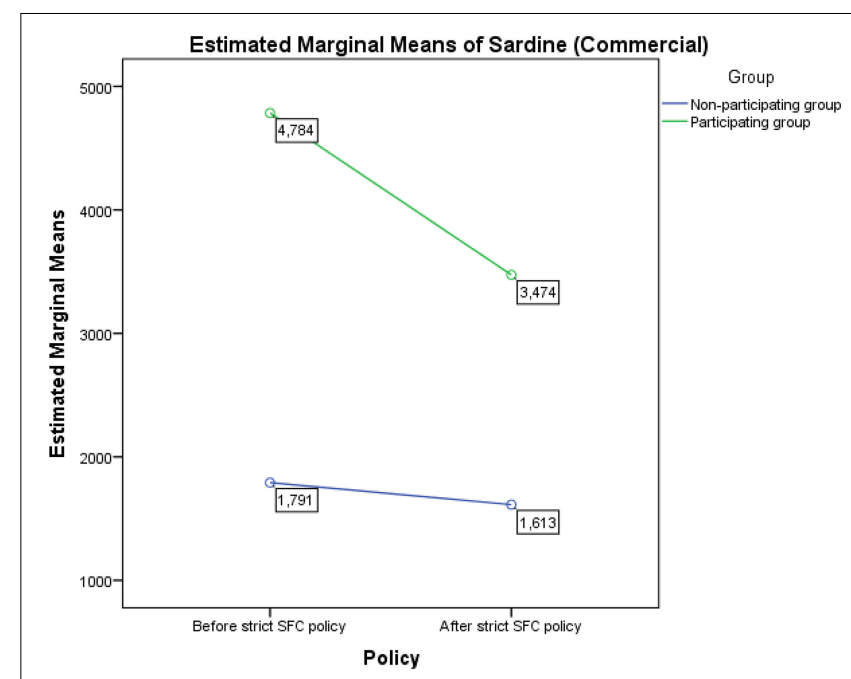

FIGURE 3 | Estimated marginal means of commercial catch for sardine (in MT) between the non-participating and participating groups, before and after the strict implementation of the SFC policy in the Visayan Sea. 


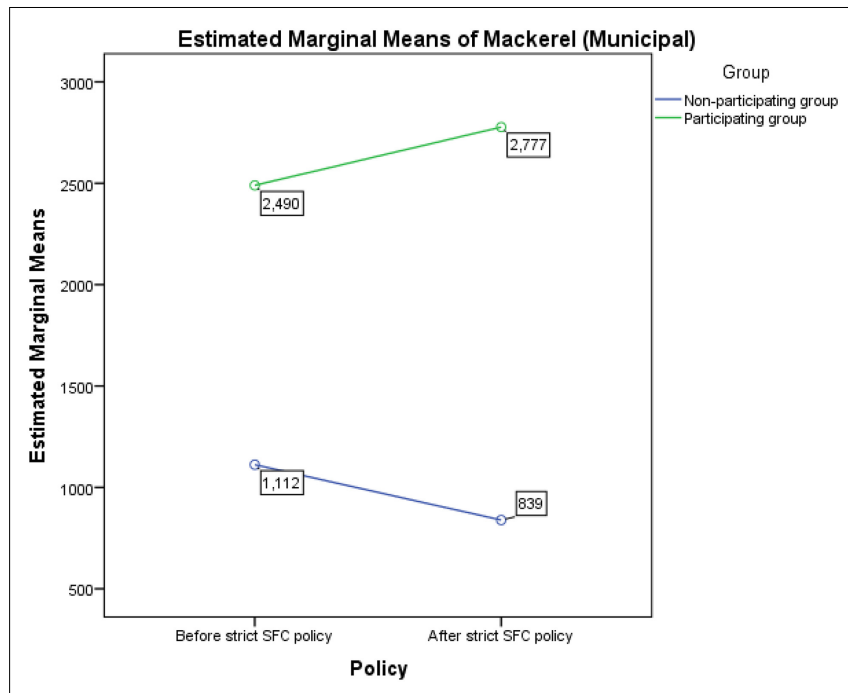

FIGURE 4 | Estimated marginal means of municipal catch for mackerel (in MT) between the non-participating and participating groups, before and after the strict implementation of the SFC policy in the Visayan Sea.

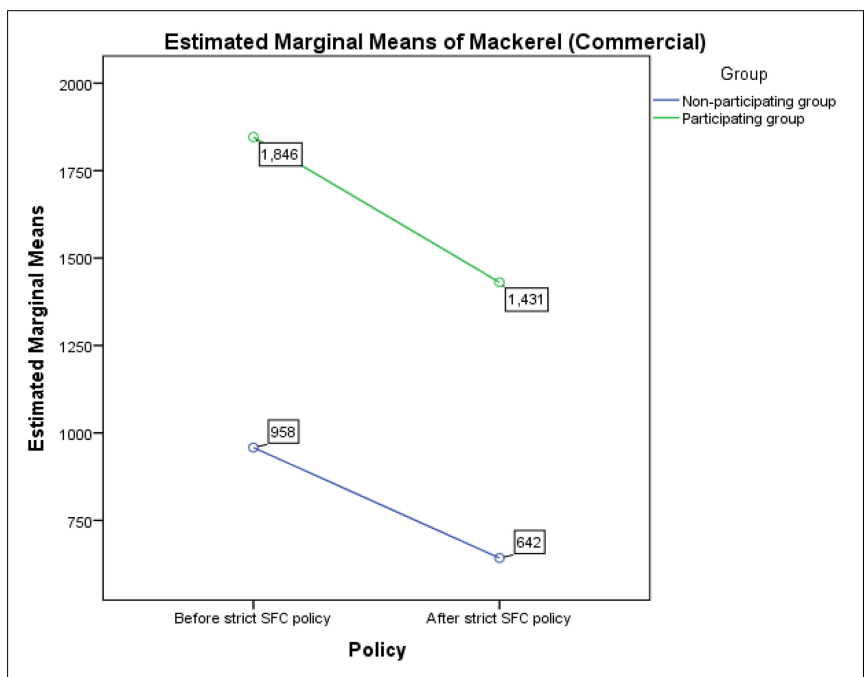

FIGURE 5 | Estimated marginal means of commercial catch for mackerel (in MT) between the non-participating and participating groups, before and after the strict implementation of the SFC policy in the Visayan Sea.

\section{Seasonal DID Analysis of Sardine and Mackerel Catch}

We also tested if there was an increase or decrease in the catch for the regulated species in the season when the SFC was not enforced. This analysis was done to check for consistency with a BFAR report that the SFC has successfully met management goals since there was a seasonal increase in small pelagic fish catch at the end of the seasonal closure (DA-BFAR, 2013b; Mesa, 2014). Results from the estimated DID model showed that the estimated coefficient on the variable of utmost interest, $G \times S \times P$ was positive and significant, indicating that sardine catch in SFC-participating provinces increased by at least 200
MT in both sectors during the open season, compared to the non-participating provinces (Figures 6, 7; Supplementary Table 6). Specifically, seasonal sardine catch increased by 286 MT in the municipal sector and $232 \mathrm{MT}$ in the commercial sector, of the SFC-participating provinces.

In contrast, we found no significant season-to-season effect of the SFC on mackerel catch among the SFC-participating provinces (Figures 8, 9; Supplementary Table 6). A slight increase in the mackerel catch was observed in the municipal sector (16 MT), while mackerel catch decreased by $66 \mathrm{MT}$ in the commercial sector, of the SFC-participating provinces following the closed season.

\section{Fishing Pressure on Other Species}

Regarding fishing pressure to other unregulated species, as shown in Supplementary Table 4, generally, among the SFCparticipating provinces, catch for the 27 species had declined. However, we cannot attribute this to the implementation of the SFC. Only the effect on Threadfin bream is significant, but weak. Given the large number of repeated tests among the 27 species, this effect may very well be spurious. That is, overall, we found no significant effect of the SFC enforcement on fishing pressure to the unregulated species in the participating provinces.

\section{Semi-Structured Interviews, Focus Group Discussion, and Key Informant Interview}

The municipal fishers that were interviewed largely target sardines and mackerels, using seine nets, gill nets, ring nets, small trawl, and other fishing gear. Most municipal fishers used motorized boats (87\%).

The interviewed fish dryers earn at least $80 \%$ of their income from fish drying. The fishes they dry were either caught by their household members or bought or loaned from fishers within their communities or neighboring municipalities. The fish vendors/fish traders/fish brokers buy and sell a variety of fishes, including sardine and mackerel.

The LGU representatives interviewed were directly involved in the fisheries management in their respective municipalities, while the fish wardens were deputized individuals, locally known as Bantay-dagat, who were tasked to help in the monitoring, control, and surveillance (MCS) of fishing activities in their respective municipal waters. They conduct seaborne patrol to deter illegal fishing activities; they also aid in rescue operations at sea.

We also interviewed members of the PNP-MG/PCG stationed in the study sites. These are members of the composite team (together with the LGU representatives, fish wardens, BFAR personnel) that conduct MCS activities and enforce laws at sea. Except for the PNP-MG/PCG respondents, all other respondents have been living in the study sites for at least 39 years, hence, they are knowledgeable about the SFC.

\section{SSI}

Majority of the municipal fishers $(N=75)$ and LGU representatives $(N=17)$ agreed that there was an observed increase in the catch for sardine in their respective municipalities 


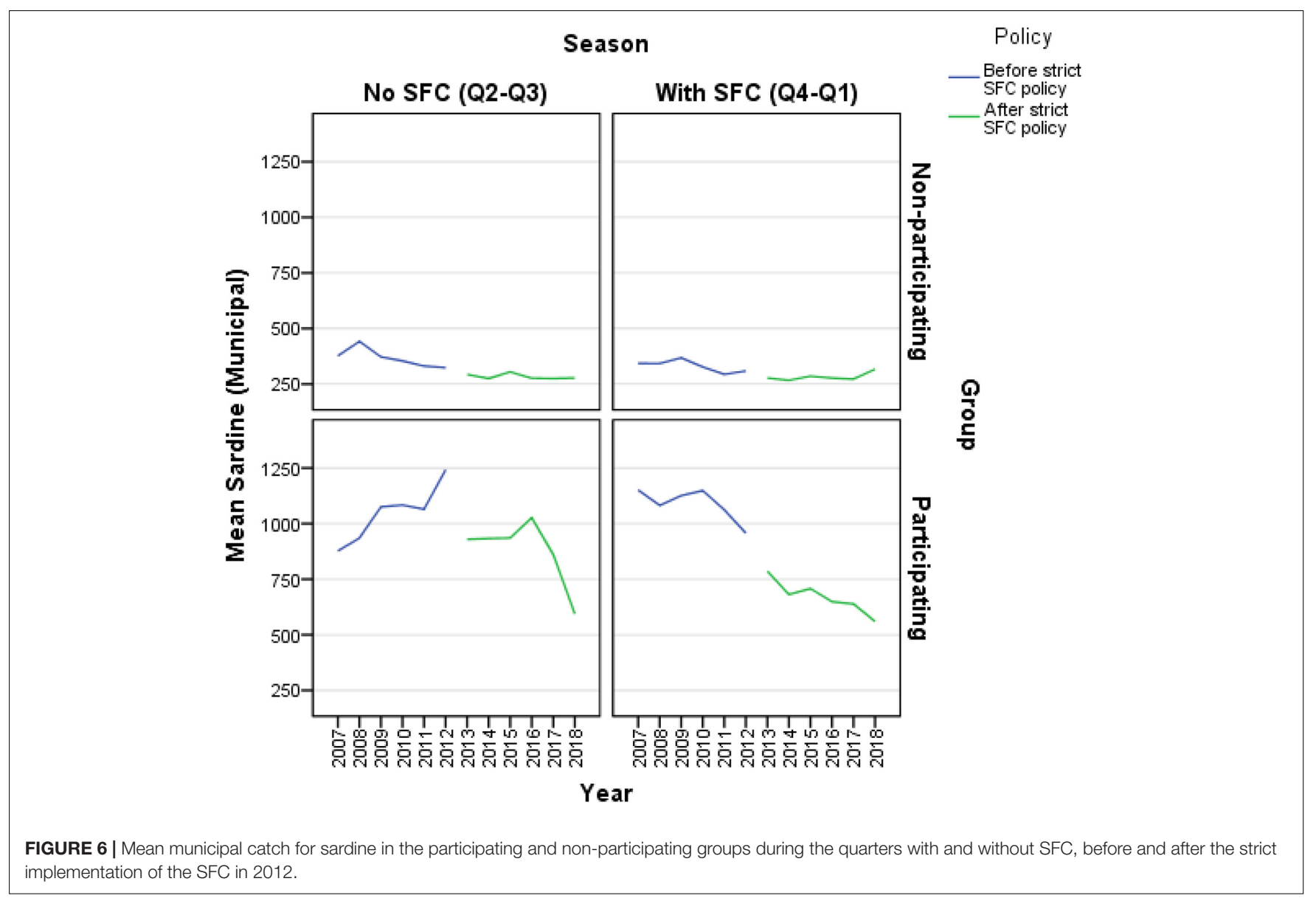

in the last 5 years (Figure 10). However, fish dryers were divided on their responses on whether there was an increase in the catch for sardines in their municipalities in recent years. Similarly, the PNP-MG/PCG had split responses: 15 of them agreed that there was an increase in the catch for sardine in their locality for the past 5 years, while the other 15 were not sure about this. Further, while 16 of the fish vendor/fish trader/fish broker respondents agreed that there was an increase in the sardine population in their areas in recent years, 11 were not sure about this and eight disagreed (Figure 10). One interesting observation noted by some of the respondents was the increase in the catch for S. lemuru (locally called tuloy), but not S. gibbosa (locally called tabagak).

Apart from the LGU representatives, municipal fisheries stakeholders interviewed were also divided on their responses when asked if there was an observed increase in the catch for mackerel in their respective municipalities in the last 5 years. For example, there were more fishers $(N=48)$, fish dryers $(N=19)$, fish wardens $(N=4)$, and PNP-MG/PCG $(N=5)$ who were neutral on their responses. In the case of the fish vendors, fish traders, and fish brokers, 14 of them agreed that catch for mackerel has increased in recent years, but 13 of them were not sure and eight of them disagreed (Figure 11). Another interesting finding was some respondents from the municipalities of Milagros (Masbate), E.B. Magalona (Negros
Occidental), and Roxas City (Capiz) said they do not catch mackerel in their areas.

\section{FGD}

Focus group discussions results revealed varying opinions from participants regarding the SFC in the Visayan Sea. For example, FGD participants in the municipality of Estancia, Iloilo did not think that the SFC is achieving its purpose because illegal fishing activities persist. They also found the SFC policy difficult to understand because its provisions were not clear, that is, it did not specify which areas and fishing gears are included in the fishing ban. The FGD participants have expressed their agreement with the fishery management goals of the SFC because according to them, the SFC gives the fishes a chance to spawn during this period. However, they also emphasized that the SFC should be implemented fairly because they had observed other fishers that continued fishing operations even when the fishing ban was in effect. When they get caught, the violators just paid the fines. These observations were echoed during the FGD in Bantayan, Cebu, wherein participants noted that some fishers continue to fish covertly and fishers using illegal fishing gears like Danish seines continue their operations. FGD participants in Carles, Iloilo also noted that fishing activities in their municipality remained the same whether the SFC was in effect or not. While FGD participants in Ajuy, Iloilo noted that fishes caught were 


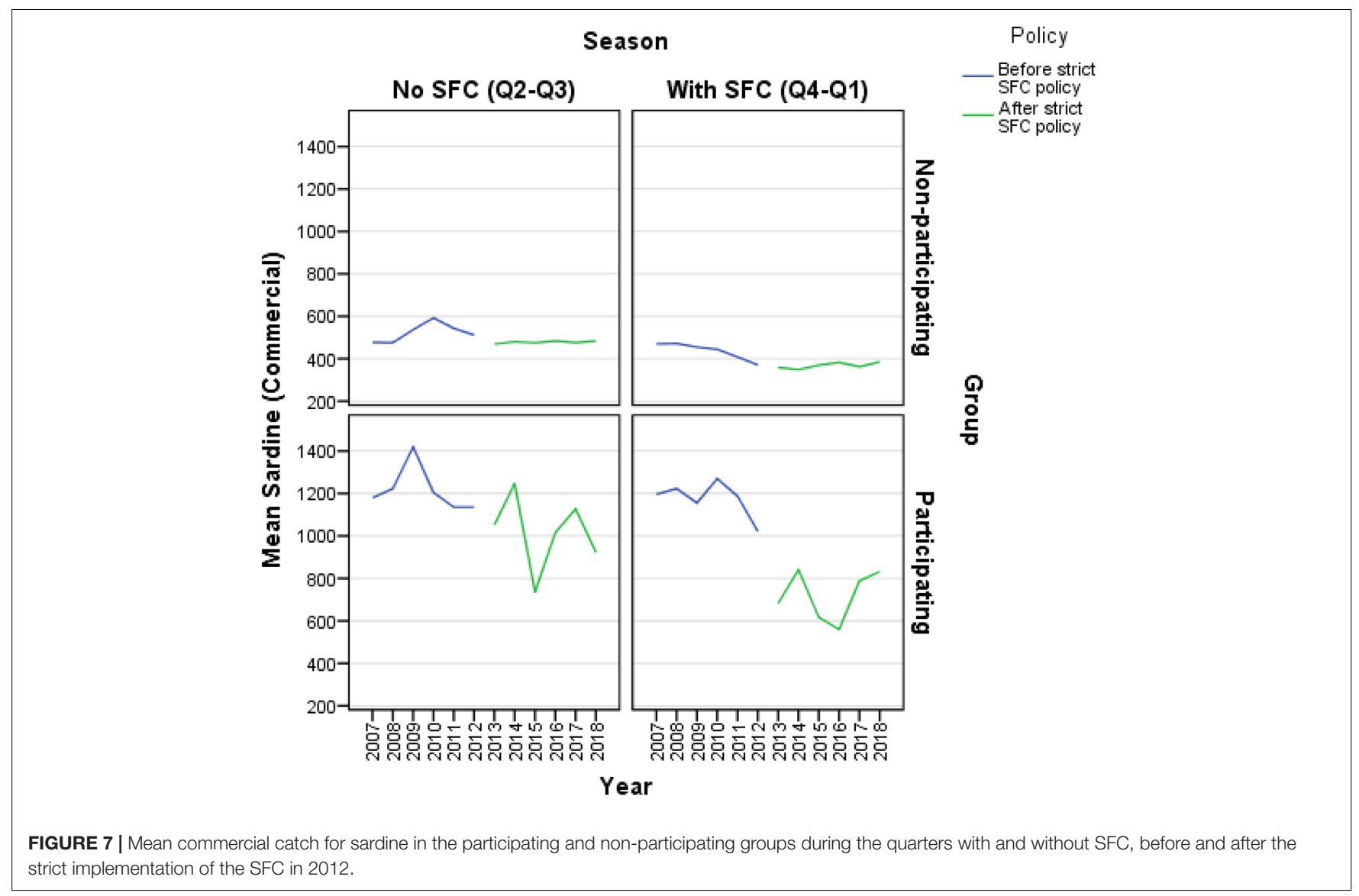

mature and bigger after the SFC was lifted, they also said that the SFC will achieve its purpose only if illegal fishers do not catch the protected species.

In contrast, FGD participants in the municipalities of Concepcion, Iloilo and Madridejos, Cebu believed that the SFC is achieving its objectives because they observed that they have bountiful fish catch during the open season. According to one participant, they did not have to fish very far from the shore since there were already fishes nearshore; they also observed many juvenile fishes.

In the case of Cadiz City, Negros Occidental, FGD participants observed a difference in their fish catch. For example, in the past, catch was plenty, but catch has dwindled in recent years. Apparently, sardine juveniles (locally called as lupoy) are caught as soon as the sardines had spawned. According to them, fishes were depleted easily due to overfishing; there were just too many fishers competing over a very scarce resource. Heavy fishing pressure often leads to capture of fishes before they reach maturation (Guanco et al., 2009). FGD participants also noted that the SFC no longer coincides with the actual breeding period of sardines because they observed presence of juvenile sardines even before the SFC is enforced. Furthermore, they said they have different fishing seasons for sardine and mackerel; that is, they catch sardines during southwest monsoon (Habagat, June-October) and mackerels during northeast monsoon (Amihan, November-May).

\section{KII}

The SFC policy was established to conserve sardines, herrings and mackerels in the Visayan Sea. According to a BFAR respondent, the SFC is achieving its objectives because there was very good compliance among fishers during the 2013-2015 SFC cycles and they observed a sudden increase in fish catch based on monitoring in markets and fish landing sites. This was corroborated by a CFARMC respondent from Negros Occidental province who observed sudden rush-in (locally called as dagsa) of sardines nearshore (normally from May-June). But according to her, this was not consistent across the years. She noted that the volume of fish catch increased, but not the fish size. For example, they used to have large sardines (classified as TL, meaning Tabagak Large) when they sort fishes during drying process, but nowadays, they cannot even get TM (Tabagak Medium). The majority of their catch consisted of TS (Tabagak Small).

Respondents from the Iloilo Provincial office also confirmed that there was an oversupply of sardines in the fishing ports at the end of the SFC. People tend to overfish the resources again after the closed season because there is an abundant supply of fish. According to respondents, even though they see an increase in the catch as per the BFAR data, the BFAR would probably say that the fisheries is still overfished. Respondents also emphasized that the government, specifically the LGUs, need to strengthen efforts on sales ban because they observed that bañeras (buckets made of plastic or steel used to haul fish catch; one bañera can 


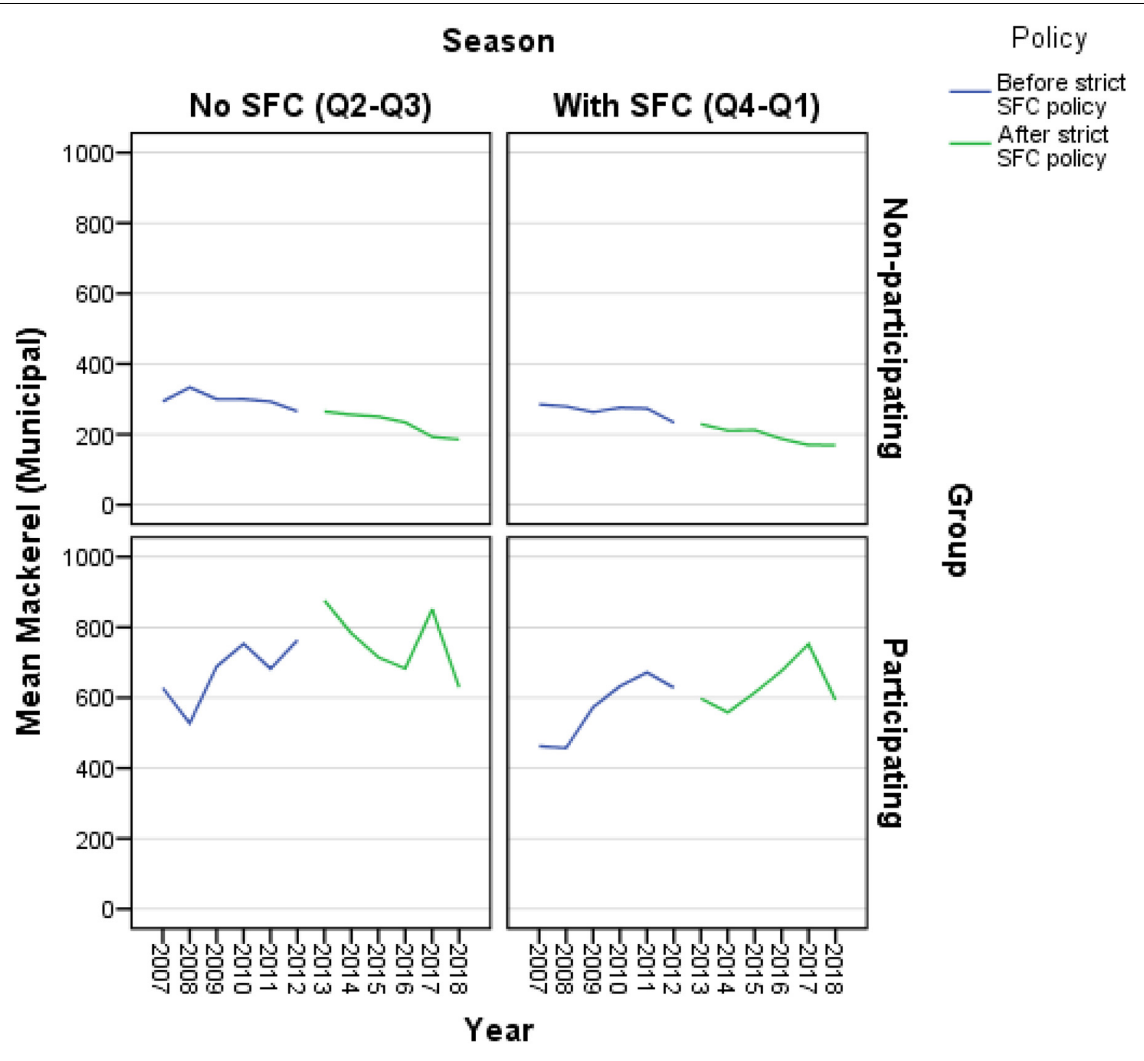

FIGURE 8 | Mean municipal catch for mackerel in the participating and non-participating groups during the quarters with and without SFC, before and after the strict implementation of the SFC in 2012.

carry $\sim 40 \mathrm{kgs}$ of fish) of sardines still flood the market during closed season. According to them, the LGUs should be on top of this because it is under their jurisdiction.

Although the BFAR cited success of the SFC in 2013-2015, they encountered problems in the succeeding years because they noticed that fishers "race to fish" before and after the SFC was declared. They also observed that species protected during the SFC were still caught and exploited at the end of the closure period and the impact on the fish stocks was much worse. Although the BFAR is strictly implementing the SFC among commercial fishers, the Bureau is lenient on the municipal level because the LGUs have jurisdiction in this area. The BFAR respondents recognized that this should not be the case since $50 \%$ of the fisheries production in the Visayan Sea is from the municipal sector. The BFAR is now actively campaigning among the LGUs in the SFC-participating municipalities to create an ordinance that will regulate the use of fine mesh nets and the catching of lupoy (sardine juveniles), which are the supposed gains from the SFC. As per a NGA respondent, "the issue right now is what happens after the SFC. If they keep on catching juveniles after the closure period, then the SFC is not making any sense."

Illegal fishing activities were identified as a perennial issue in the Visayan Sea. For example, the C/MFARMC respondents noted that while they implement the SFC in their respective municipalities, there are too many violators from within (i.e., in addition to non-compliance with the SFC, fishers use fine mesh nets) and outside their municipalities (i.e., commercial fishers encroaching in the municipal waters). Poachers have faster boats making it difficult for fish wardens and small-scale fishers to catch them. Respondents also noted lapses in the monitoring of the SFC because they cannot police all the coastal barangays. For example, fish wardens in certain SFC-participating municipalities cannot fully implement the SFC because they do not have the capacity and resources. Unlike other members of the MCS team who receive salary for their services, some fish wardens only receive allowances, while fish wardens in other areas serve as volunteers. Thus, the LGUs cannot oblige them to police the municipal waters.

On the part of the LGUs, respondents found the SFC policy difficult to implement because it is vague and has too many loopholes. The LGU respondents said they do not know how to fully implement the SFC policy because of the lack of specific implementing rules and regulations on the SFC policy. They cited a case wherein they apprehended a fisher selling banned fishes in a fishing port while the SFC in effect, but the fisher argued that he caught the fishes from another municipality (with a certification from that municipality). They expressed their concern over getting into a sticky situation with the violators because of this. They further said that even the BFAR personnel assigned in the fishing ports are not sure how to 


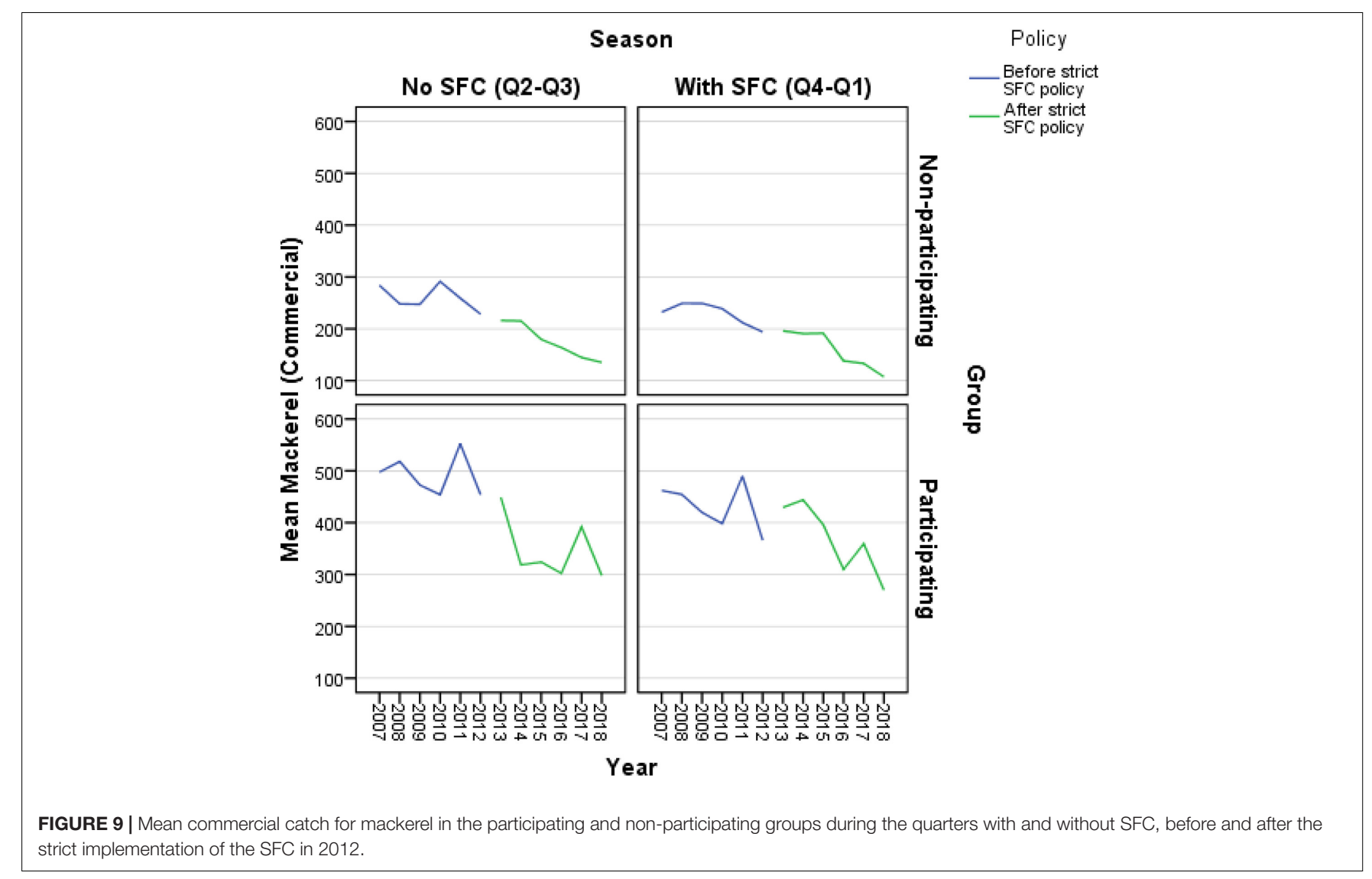

handle SFC violations. For example, they have encountered a fisher in possession of the banned species, but the BFAR personnel present during that time said they should allow it because the catch was not that much. However, they do not have any basis for what qualifies for a small catch. The BFAR respondents admitted that the objectives of the SFC are not very clearly stated and the SFC policy did not mention municipal and commercial fishers, nor specific fishing gears banned. It broadly stated that it is prohibited, under the law, to catch the regulated species. Thus, there is a varying interpretation of the SFC policy.

Another critical issue raised by a C/MFARMC respondent is that some small-scale fishers are heavily dependent on the fishery resources. While the big fishing operators have other sources of income and can fish further out to sea during the closed season, this is not the case for the small-scale fishers. Several respondents said violations of the SFC policy are inevitable because those who depend on fishing for their day-to-day survival continue to fish. And unless alternative livelihoods for the affected stakeholders are put into place, non-compliance with the SFC will continue. For example, some LGU respondents admitted that they are not implementing the SFC in their municipality because of the lack of alternative livelihood for the affected fishers. The BFAR respondents acknowledged their agency's shortfall in providing alternative livelihoods to affected stakeholders.

\section{DISCUSSION}

The BFAR claims success of the SFC, particularly in improving the catch for the regulated species. For example, the BFAR reported that sardine catch has increased seasonally in 2013 following the SFC (DA-BFAR, 2013b, 2018; Mesa, 2014). This increase is attributed by the BFAR to its intensive information, education, and communication (IEC) campaign and stricter MCS activities (Mesa, 2014). However, our study argues that the mere comparison of fish catches before and after the implementation of the SFC program in a normal seasonal cycle is misleading because fishers "race to fish" as soon as the open season begins, thus, causing the seasonal catch increase reported by the BFAR. This has been confirmed by the BFAR representatives during an interview; key informants reported that fishers indeed tend to "race to fish" as soon as the SFC is declared and immediately after the fishing ban is lifted. Further, the claimed success of the SFC according to the BFAR is not convincing because fishing effort is indeed expected to decline during the SFC and spike immediately after the SFC is lifted. If no such decline followed by an increase were reported, this would likely indicate that the SFC was not adequately enforced. Furthermore, the reported increase in the catch for sardine is based on only 2 years of observations following stricter enforcement of the SFC. This may not be conclusive for evaluating SFC success because 2 years of implementation is a very short period to observe a meaningful impact of the policy since previous studies on sardine populations 


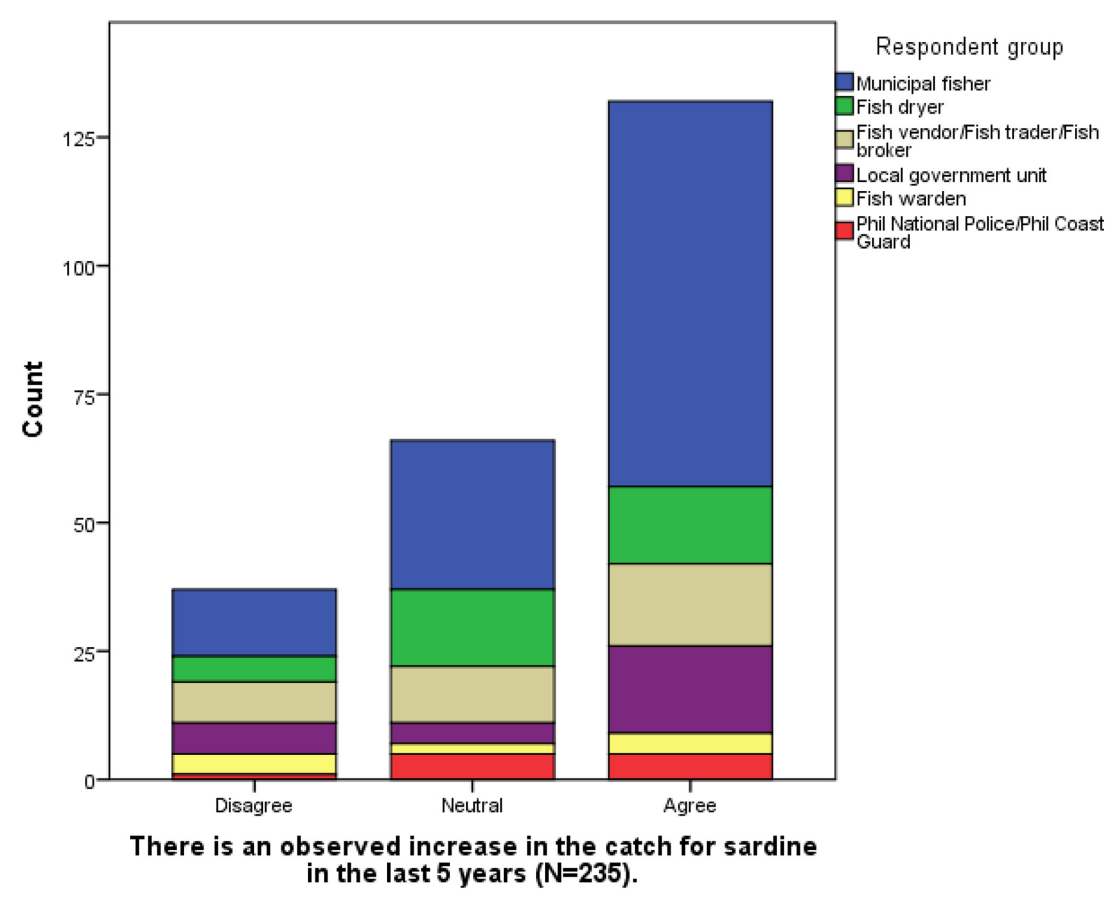

FIGURE 10 | Municipal stakeholders' level of agreement with the statement "There is an observed increase in the catch for sardine in the last 5 years."

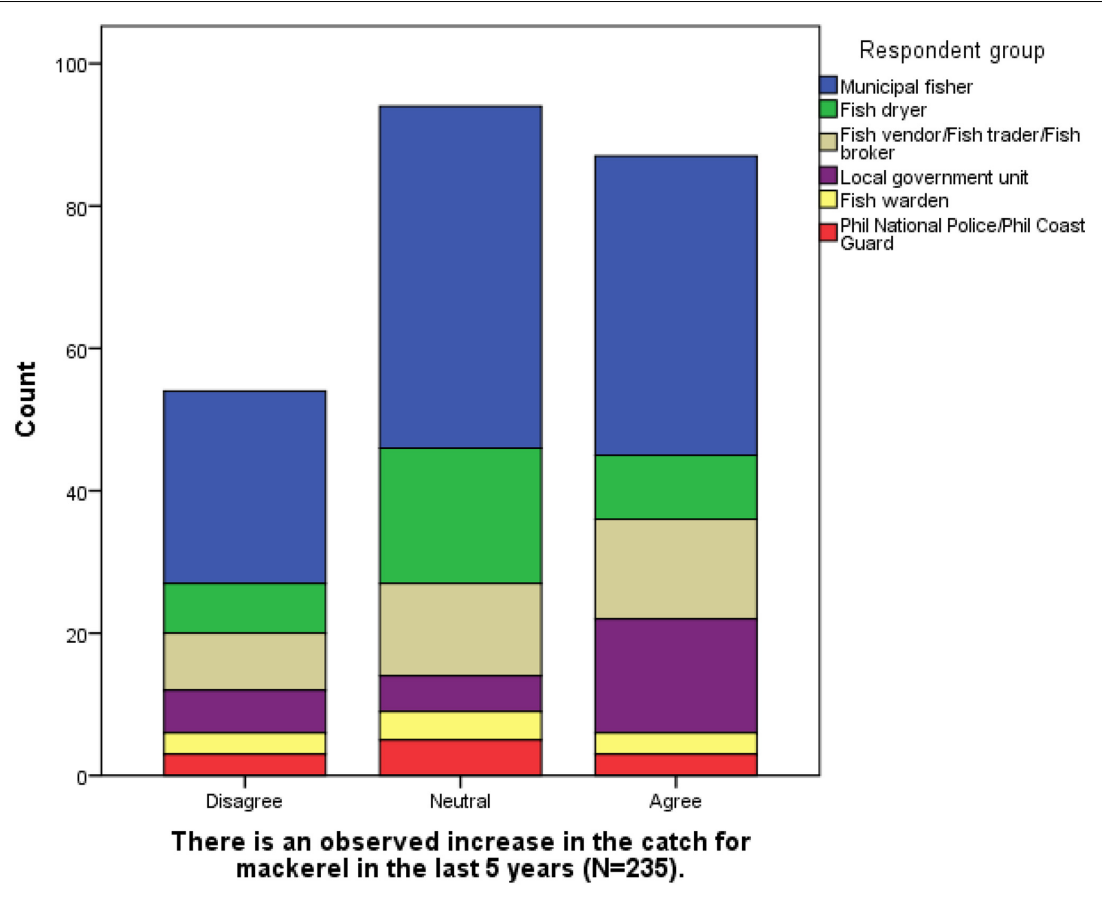

FIGURE 11 | Municipal stakeholders' level of agreement with the statement "There is an observed increase in the catch for mackerel in the last 5 years."

in the Philippines indicate that these species take about 23 years to reach sexual maturity (Willette et al., 2011). In a study of seasonal closure effects in the Gulf of Mexico shrimp fishery, increases in overall yield and values were documented in the first year, although no benefits were observed in the second year (Beets and Manuel, 2007). These findings suggest that evaluation of success of SFCs should be based on analysis of data from several years.

We expanded upon BFAR's data by reporting results over a longer time frame. Results of our seasonal analysis showed a 
significant increase in the municipal and commercial catch for sardine in the participating group during the quarters in a year when the SFC is not implemented. These results corroborated the BFAR's claims of an increasing catch for sardine in the months following the SFC in 2011-2012 and 2012-2013 (Mesa, 2014). These findings might also be what the municipal fisheries stakeholders cited as the observed increase in the catch for sardine in their respective municipalities in the last 5 years (Figure 10). However, our analysis showed that catch for sardine has decreased overall when examining interannual rather than seasonal trends. The decrease was not significant.

Interview results corroborate our DID findings for mackerel since the majority of the municipal fisheries stakeholders interviewed were not sure as to whether there was an increase in the catch for mackerel in the last 5 years (Figure 11). This is not surprising since some respondents in Milagros (Masbate province), E.B. Magalona (Negros Occidental province), and Roxas City (Capiz province) said they do not have mackerel catch in their area. Respondents from Cadiz City (Negros Occidental province) claimed they catch mackerel during the northeast monsoon (Amihan; November-May), which implies that their fishing season for mackerel in Cadiz City overlaps with the SFC in the Visayan Sea.

In general, the majority of the respondents claimed that the SFC is strictly implemented in their own municipalities, but they doubt if this is the case in other municipalities. Compliance with the SFC among municipal and commercial fishers appears to remain a challenge because of the lack of alternative livelihoods for the affected fishers. Apparently, the implementation of the SFC has become a secondary concern to the surrounding fishing communities around the Visayan Sea because illegal fishing activities remain rampant in these areas. The illegal fishing activities can be partly attributed to the relatively low fines for violations and lenient implementation of fishery laws at the municipal level. The respondents recognize that the objectives of the SFC will be met only if illegal fishing activities are addressed. Further, the lack of implementing guidelines for the SFC inhibits proper enforcement of this policy. In spite of these management gaps, municipal fisheries stakeholders said the SFC helps slow down illegal fishing because of the MCS activities during the SFC. These findings reflect on the quality of management in the Visayan Sea, and the uneven implementation of, and support for, the SFC. In a study that examined six seasonal closures in the Commonwealth of Puerto Rico, small-scale fishers similarly perceived seasonal closures as effective fishery management measures although these measures did not always improve the fisher's livelihoods nor result in their support for these measures (Agar et al., 2019).

Since the goal of this policy is to conserve the regulated stocks, the decline in interannual sardine catch after strict SFC implementation suggests that this goal has not yet been fully achieved. In general, an SFC management strategy is primarily based on effort control; it aims to reduce fishing mortality by limiting the fishing activity to an appropriate level thereby increasing the stock size. However, Beets and Manuel (2007) argue that predicting fishing mortality based on effort control may be difficult because that would depend on how fishers respond to set regulations. For example, fishers affected by the SFC in the Visayan Sea "race to fish" before and after the SFC is lifted to compensate for their low catches during the SFC period, while other fishers continue to fish covertly to survive. It is important to note that small pelagic fishes, such as sardine and mackerel, serve as a main source of inexpensive animal protein, especially for the poor and lower-income populations in the country. Food security is a critical consideration when introducing more traditional fishing controls, such as closed seasons and no-take areas, and alternative livelihoods that can provide immediate food or cash needs are to be preferred above those that require longer-term investments to realize benefits (Muallil et al., 2012, 2013). The lack of alternative livelihood opportunities for the SFC-affected fishers is not unique to the Visayan Sea because government funding for livelihoods is limited and opportunities outside the fishery are generally lacking in the Philippines (Muallil et al., 2013).

The noted prevalence of illegal fishing in the Visayan Sea and commercial fishing in the municipal waters are some of the factors that hinder the success of the SFC policy because whatever gains accrued during the 3-month SFC are readily lost to illegal and commercial fishing operations, especially given that some LGUs allow commercial fishing within municipal waters. For example, some coastal towns in the Philippines allow commercial fishing operations from $10.1 \mathrm{~km}$ seaward through municipal ordinances. This has serious implications to the small-scale fishers because of increased competition with commercial fishers in reduced ranges due to the permitting of commercial fishing in municipal waters and the enclosure from the SFC. These findings imply that the SFC policy should be properly enforced and complied with, and an alternative source of livelihood should be provided to the affected stakeholders before positive results can be expected.

Studies have shown that the design of SFCs presents a challenge because the net benefits to the fishery or other resources are often unknown (Sanchirico and Wilen, 2001; Sanchirico, 2005). Clearly, the implementation of the SFC alone is not enough to effect positive results in the management of sardine and mackerel in the Visayan Sea, particularly with regard to the goal of increasing fish catch. Although there might be positive effects on the overall population size of these species, this remains unknown, especially since CPUE data for this fishery are unavailable.

Fishers also reported shifting to catching other species during the 3-month fishing ban (Bagsit, 2020). DID estimates for the other 27 species we analyzed showed no significant shift in fishing pressure to these species, suggesting that increased fishing pressure on these species did not compensate for lost income or sources of protein during the SFC.

Despite being in effect for eight decades now, the science behind the SFC in the Visayan Sea continues to be challenged because of the lack of supporting evidence on the causes of the decline in the regulated species. This is particularly important for sardine and mackerel because studies in other areas indicate that their populations are sensitive to ocean climate and productivity (Checkley et al., 2017; Spijkers and Boonstra, 2017; Das et al., 2020). Therefore, a careful study of the SFC 
and the spawning habitat used by sardine and mackerel in this area is crucial to ensure that management efforts, and thus government expenditure, translate to measurable outcomes toward sustainable fisheries in the Visayan Sea. Understanding the spatial and temporal constraints on spawning habitat and if this habitat is associated with specific oceanic conditions for sardine and mackerel in the Visayan Sea is imperative because, if these species are shown to use a subset of habitats in the Visayan Sea or spawn over a more contracted season, then it may be possible to protect the spawning stock in a more targeted manner.

Previous studies have shown that fish abundance fluctuates as a result of fishing activity, and productivity can shift between high and low regimes unrelated to abundance (Gilbert, 1997; Mantua and Hare, 2002; Axenrot and Sture, 2003; MacKenzie et al., 2007; Vert-pre et al., 2013). For example, the collapse of stocks of Peruvian anchoveta (Engraulis ringens), the Alaskan pollock (Theragra chalcogramma), and the Atlantic cod stock off eastern Canada (Gadus morhua) have been attributed to the combined effects of changing ecosystems and overfishing (Alheit and Niquen, 2004; Bailey, 2011; Lilly et al., 2013; Skern-Mauritzen et al., 2015). In addition to variations between productivity regimes, climate change is affecting many living marine resources. In a review paper that looks at the relationship between climate and populations of anchovy and sardine, Checkley et al. (2017) conclude that anchovy and sardine populations vary in response to climate. While fishing may change the fluctuations in anchovy and sardine stocks, it neither causes nor prevents these fluctuations. Several studies have also pointed out the wide changes in the production levels of sardine and anchovy fisheries, which has sustained periods of high and low catch occurring almost in synchrony in different systems, suggesting a large-scale, interdecadal phenomenon that links these events rather than just the effect of independent fishing pressure (Kawasaki and Omori, 1988; Lluch-Belda et al., 1989; Kawasaki et al., 1991; Lluch-Cota et al., 1997). Kawasaki and Omori (1988) observe that the fluctuations in sardine and anchovy abundances in Japan, California, and Peru-Chile Systems are associated with globally sustained warm periods, while the high anchovy high and low sardine abundances are associated with sustained cold periods. On the contrary, Crawford et al. (1987) report an opposite pattern for sardineanchovy abundances in the Benguela System.

Similar findings have been reported for mackerel (Overholtz et al., 2011; Kanamori et al., 2019). Overholtz et al. (2011) observed that changes in the spatial and bathymetry distribution of the Northwest Atlantic stock of Atlantic mackerel (Scomber scombrus) are related to interannual temperature variability and gradual warming. Examination of the longterm changes in spawning patterns and spawning ground of the chub mackerel (Scomber japonicus) in the western North Pacific reveals extension of the spawning period and movement of the geographic location of the spawning ground northward in relation to changes in sea surface temperature (Kanamori et al., 2019).

Notwithstanding the current debate on the causes of these variabilities in the environment, fisheries management agencies need to acknowledge that irregular changes in productivity are common, and that harvest regulation and management targets need to be flexible and robust to productivity changes (Vert-pre et al., 2013). In the case of the SFC in the Visayan Sea, in addition to monitoring fish catch landings, it will be valuable for resource managers to understand the ecosystem drivers of fish stock productivity in the area because fish stock production is dependent on the physical and biological conditions of the ecosystem (Skern-Mauritzen et al., 2015; Fowler et al., 2018; Kurota et al., 2020). This is fundamental for the BFAR management especially since the agency has recently adopted the ecosystem approach to fisheries management in the Visayan Sea (DABFAR, 2018). One of the main pillars of this approach is the inclusion and consideration in management of the ecosystem processes that impact fish stock production (Skern-Mauritzen et al., 2015).

We recommend that the BFAR should consider adopting a more direct and effective method of controlling fishing mortality other than SFCs, such as controlling for catch levels or landings, or controlling access to the resource (Caddy, 1984). However, we recognize that, although these strategies may also have associated challenges, such as funding requirements and sufficient staffing available to monitor catch levels in realtime throughout the region. Given the limited resources of the BFAR and the LGUs, strict monitoring of fish landings in the market and landing sites might be a more feasible strategy, rather than the more costly and risky MCS activities at sea. Similar recommendations might help improve management of data poor fisheries in other regions in lieu of using seasonal closures.

It would also be helpful if the BFAR and National Fisheries Research and Development Institute (NFRDI) allow public access to the National Stock Assessment Program data they have collected to facilitate a more robust analysis of their programs, which can be beneficial to the stakeholders and policymakers. Homologous datasets, such as fish catch, landings, fish stock size, fish quotas, and coastal habitat maps, are publicly available in a number of organizations and countries (e.g., National Oceanic and Atmospheric Administration, United States; Department of Environment, Food and Rural Affairs, United Kingdom; Australian Fisheries Management Authority, Australia; National Parks Board, Singapore). Making such datasets available allows independent researchers to use them to study questions relevant to fisheries management and accelerates scientific progress.

The BFAR must also develop clear metrics for evaluating the success or failure of the SFC policy. This will ultimately aid informed decision-making and lead to an improved fisheries management framework, appropriate programs for fisheries stakeholders, and efficient and responsible spending of government funds. Finally, there should be an independent body that will audit the performance of the BFAR in the management of the fisheries not only in the Visayan Sea, but throughout the country, to identify the gaps and help strengthen the role of the BFAR in the conservation, protection, and monitoring of the fisheries in the country. There are several academic institutions in the country that can help in this aspect. 


\section{CONCLUSION}

Based on a BACI design analysis with a DID estimation strategy, the effect of the SFC policy on sardine and mackerel was evaluated. Although seasonal analysis of the catch for sardine showed a significant increase in the municipal and commercial catch for sardine in the participating group during the open season (Q2-Q3), overall, the SFC policy has no significant effect on the sardine interannual catch among SFCparticipating provinces after the strict enforcement of the SFC in 2012. Further, there was no significant effect of the SFC policy on the catch for mackerel even during the open season. There was an increase in the interannual municipal catch for mackerel after 2012; however, the increase was not significant. These findings do not support the claims by the BFAR on the increasing catch of sardine in the Visayan Sea. These results are also contrary to the perceptions of the municipal fisheries stakeholders in the participating municipalities of the SFC who have indicated increasing catch for sardine catch in the Visayan Sea in the last 5 years. Further, while fishers reported a shift to catching other aquatic species during the 3-month fishing ban (Bagsit, 2020), the effect on other species was negligible based on our analysis of their catch. Some of these differences between catch statistics and stakeholders' perception may reflect the integration of catch data over a larger spatial area which includes regions of the Visayan Sea where there have been variations in the extent of SFC enforcement and the amount of illegal fishing reported by locals.

The fluctuation in the abundance of the regulated species in the Visayan Sea may be a result of the combined effects of fishing activity and productivity shifts driven by changes in the environment. Understanding the underlying mechanisms that govern the fluctuations in the abundance of fish stocks is critical to the appropriate management of the fisheries. In addition to monitoring fish catch landings, it will be valuable for the BFAR management, through the NFRDI, to collect biophysical data (e.g., sea temperature, chlorophyll-a, dissolved oxygen, salinity) to aid in understanding the ecosystem drivers of fish stock productivity in the Visayan Sea. Several studies have shown that physical and biological conditions of the ecosystems in other areas greatly influence fish migration, mortality rates, and recruitment (Kawasaki and Omori, 1988; LluchBelda et al., 1989; Kawasaki et al., 1991; Lluch-Cota et al., 1997; Overholtz et al., 2011; Kanamori et al., 2019). Many of these variables can be remotely sensed and data from remote sensing are publicly available, allowing managers and scientists to obtain information on environmental variables associated with fish habitat inexpensively. However, some expertise, training, and potentially fishery-independent survey data would need to effectively connect these variables with fish habitat use patterns.

\section{DATA AVAILABILITY STATEMENT}

The original contributions presented in the study are included in the article/Supplementary Material, further inquiries can be directed to the corresponding author/s. The secondary datasets analyzed are publicly available. This data can be found here: https://openstat.psa.gov.ph/.

\section{ETHICS STATEMENT}

This study was reviewed and approved by the University and Medical Center Institutional Review Board (UMCIRB) at East Carolina University (ECU). The respondents provided their written informed consent to participate in this study.

\section{AUTHOR CONTRIBUTIONS}

FB contributed to conception and experimental design, investigation, data collection and analysis, research administration, and writing of original draft of the study. EF contributed to experimental design and data analysis of the study. RA and HM contributed to conception and experimental design of the study. All authors contributed to manuscript revision, read, and approved the submitted version.

\section{FUNDING}

This study is part of the dissertation of FB that was funded through the support of her adviser, Dr. David Griffith, and the Department of Coastal Studies, East Carolina University (ECU), in North Carolina, United States. RA was supported by an Alfred P. Sloan Foundation Research Fellowship.

\section{SUPPLEMENTARY MATERIAL}

The Supplementary Material for this article can be found online at: https://www.frontiersin.org/articles/10.3389/fmars. 2021.640772/full\#supplementary-material

Supplementary Table 1 | List of provinces in the participating and non-participating groups in the $\mathrm{BACl}$ analysis.

Supplementary Table 2 | Categorical variable information for sardine. Supplementary Table 3 | Categorical variable information for mackerel.

Supplementary Table 4 | DID estimates for the 27 species not regulated under the SFC in the Visayan Sea.

Supplementary Table 5 | DID estimates for municipal and commercial interannual catch for sardine and mackerel.

Supplementary Table 6 | DID estimates for municipal and commercial seasonal catch for sardine and mackerel. 


\section{REFERENCES}

Abadie, A. (2005). Semiparametric difference-in-differences estimators. Rev. Econ. Stud. 72, 1-19. doi: 10.1111/0034-6527.00321

Agar, J., Shivlani, M., Fleming, C., and Solís, D. (2019). Small-scale fishers' perceptions about the performance of seasonal closures in the commonwealth of Puerto Rico. Ocean Coast. Manag. 175, 33-42. doi: 10.1016/j.ocecoaman. 2019.03.025

Alheit, J., and Niquen, M. (2004). Regime shifts in the Humboldt Current ecosystem. Proüess Oceanogr. 60, 201-222. doi: 10.1016/j.pocean.2004.02.006

Arendse, C. J., Govender, A., and Branch, G. M. (2007). Are closed seasons an affective mean of increasing reproductive output? A per-recruit simulation using the limpet Cymbula granatina as a case history. Fish. Res. 85, 93-100.

Armada, N. B. (1999). Assessment and Management of Small Pelagic Fisheries in the Visayan Sea. Iloilo. 44. doi: 10.1515/9783110808384-003

Axenrot, T., and Sture, H. (2003). Predicting herring recruitment from young-ofthe-year densities, spawning stock biomass, and climate. Limnol. Oceanogr. 48, 1716-1720. doi: 10.4319/lo.2003.48.4.1716

Babcock, J. P., Found, W. A., Freeman, M., and O'Malley, H. (1931). Report of the International Fisheries Commission Appointed under the Northern Pacific Halibut Treaty. IFC Report 1. Seattle, WA: International Pacific Halibut Commission, 31 .

Bagsit, F. U. (2020). The political ecology of the seasonal fishery closure in the Visayan Sea, Philippines. A Ph D. Submitted to the Faculty of the Department of Coastal Studies. Greenville, NC: East Carolina University, 240.

Bailey, K. M. (2011). An empty donut hole: the great collapse of a North American fishery. Ecol. Soc. 16:2.

Bailey, K. M., and Houde, E. D. (1989). Predation on eggs and larvae of marine fishes and the recruitment problem. Adv. Mar. Biol. 25, 1-83. doi: 10.1016/ s0065-2881(08)60187-x

Bayate, D. E., and Mesa, S. V. (2012). Visayan Sea Sardine Stock and its Fishery Conservation Initiatives in Western Visayas, Philippines: A Review. Bureau of Fisheries and Aquatic Resources, National Stock Assessment Program, Regional Office 6. Iloilo City: Bureau of Fisheries and Aquatic Resources, 26.

Beets, J., and Friedlander, A. (1999). Evaluation of a conservation strategy: a spawning aggregation closure for red hind, Epinephelus guttatus, in the U.S. Virgin Islands. Environ. Biol. Fish. 43, 217-241.

Beets, J., and Manuel, M. (2007). Temporal and Closed seasons Used in Fisheries Management: A Review with Application to Hawai'i. Available online at: http://dlnr.hawaii.gov/coralreefs/files/2015/02/BeetsTempClosuresRpt08.pdf (accessed March 9, 2017).

Bell, F. H. (1969). Agreements, Conventions, and Treaties Between Canada and the United States of America with respect to the Pacific Halibut Fishery, 1st Edn. Seattle, WA: Canada and the United States of America with respect to the Pacific Halibut Fishery.

Bernard, R. (2017). Research Methods in Anthropology, Qualitative and Quantitative Approaches, 6th Edn. Lanham MD: Rowman \& Littlefield.

Brodziak, J. K. T., Mace, P. M., Overholtz, W. J., and Rago, P. J. (2004). Ecosystem trade-offs in managing new england fisheries. Bull. Mar. Sci. 52:2004.

Caddy, J. F. (1984). "Indirect approaches to regulation of fishing effort," in FAO (1984) Papers Presented at the Expert Consultation on the Regulation of Fishing Effort (Fishing Mortality). Rome, 17-26 January 1983. A Preparatory Meeting for the FAO World Conference on Fisheries Management and Development, Vol. Suppl.2, (Rome: FAO), 214.

Carpenter, K. E., and Springer, V. G. (2005). The center of the center of marine shore fish biodiversity: the Philippine Islands. Environ. Biol. Fish. 72, 467-480. doi: 10.1007/s10641-004-3154-4

Checkley, D. M. Jr., Asch, R. G., and Rykaczewski, R. R. (2017). Climate, anchovy, and sardine. Annu. Rev. Mar. Sci. 9, 469-493. doi: 10.1146/annurev-marine122414-033819

Cheung, W. W. L., de Mitchelson, Y. S., Braynen, M. T., and Gittens, L. G. (2015). Are the last remaining Nassau grouper Epinephelus striatus fisheries sustainable? Status quo in the Bahamas. Endangered Species Res. 20, 2013.

Clarke, J., Bailey, D. M., and Wright, P. J. (2015). Evaluating the effectiveness of a seasonal spawning area closure. ICES J. Mar. Sci. 72, 2627-2637. doi: 10.1093/icesjms/fsv144
Claudet, J., and Guidetti, P. (2010). Improving assessments of marine protected areas. Aquat. Conserv. Mar. Freshwater Ecosyst. 20, 239-242. doi: 10.1002/aqc. 1087

Conner, M. M., Saunders, W. C., Bouwes, N., and Jordan, C. (2016). Evaluating impacts using a BACI design, rations, and a Bayesian approach with focus on restoration. Environ. Monit. Assess. 188:555.

Crawford, R. J. M., Shannon, L. V., and Pollock, D. E. (1987). The Benguela ecosystem. IV: the major fish and invertebrate resources. Oceanogr. Mar. Biol. A. Rev. 25, 353-505.

DA-BFAR (2011). BFAR Chief Bats for Resource Conservation. Available online at: https://www.bfar.da.gov.ph/newsarchives.jsp?id=202 (accessed February 20, 2018).

DA-BFAR (2012). Commercial Fishers Support Government Sardine Closed Season for the Visayan Sea. Available online at: https://www.bfar.da.gov.ph/ newsarchives.jsp?id=183 (accessed June 17, 2016).

DA-BFAR (2013a). Fisheries Administrative Order No. 167-3, s. 2013. Amending Fisheries Order No. 167 series of 1989. Available online at: https://www.bfar.da. gov.ph/LAW?fi=468\#post (accessed May 28, 2018).

DA-BFAR (2013b). Success of Sardine Closure, Not Impossible for Galunggong. Available online at: https://www.bfar.da.gov.ph/newsarchives.jsp?id=140 (accessed October 16, 2016).

DA-BFAR (2014). Philippine Fisheries Profile 2014. Ghaziabad: DA-BFAR, 36.

DA-BFAR (2018). Management Framework for the Conservation, Protection and Restoration of the Visayan Sea. Ghaziabad: DA-BFAR, 30.

Dalzell, P., Corpuz, P., Arce, F., and Ganaden, R. (1990). Philippine small pelagic fisheries and their management. Aquacult. Fish. Manag. 21, 77-94. doi: 10. 1111/j.1365-2109.1990.tb00384.x

Dalzell, P., and Ganaden, R. (1987). The Overfishing of Small Pelagic Fish Stocks in the Philippines. Available online at: http://www.fao.org/3/a-bm734e.pdf (accessed May 27, 2018).

Das, I., Lauria, V., Kay, S., Cazcarro, I., Arto, I., Fernandes, J. A., et al. (2020). Effects of climate change and management policies on marine fisheries productivity in the north-east coast of India. Sci. Total Environ. 724:138082. doi: 10.1016/j. scitotenv.2020.138082

Department of Agriculture-Bureau of Fisheries and Aquatic Resources (DA-BFAR) (1939). Fish and Game Administrative Order No. 13, s. 1939. Regulations Establishing Closed Season for the Conservation of Sardines and Herrings. Available online at: https://www.bfar.da.gov.ph/LAW?fi=56\#post (accessed February 24, 2020).

Everson, A. (1986). Closed Season as a Management Policy in Lobster Fisheries. NOAA. Southwest Fisheries Center, Administrative Report H-86-7. Washington, DC: NOAA.

FAO (2020). State of the World Fisheries and Aquaculture: Sustainability in Action. Rome: FAO, 224.

Farmer, N. A., Gowan, T. A., Powell, J. R., and Zoodsma, B. J. (2016). Evaluation of alternatives to winter closure of black sea bass pot gear: projected impacts on catch and risk of entanglement with north right whales Eubalaena glacialis. Mar. Coast. Fish. 8, 202-221. doi: 10.1080/19425120.2016.1146181

Fenberg, P. B., Caselle, J. E., Claudet, J., Clemence, M., Gaines, S. D., Antonio Garci'a-Charton, J., et al. (2012). The science of European marine reserves: status, efficacy, and future needs. Mar. Policy 36, 1012-1021. doi: 10.1016/j. marpol.2012.02.021

Ferrer, A. J. (2009). Evaluation of Fisheries Management Options for the Visayan Sea, Philippines: The Case of Northern Iloilo. Research Report No. 2009RR5. Published by the Economy and Environment Program for Southeast Asia (EEPSEA). Port Aransas, TX: EEPSEA.

Food and Agriculture Organization (FAO) (2000). Information on Fisheries Management in the Republic of the Philippines. Available online at: http://www. fao.org/fi/oldsite/FCP/en/PHL/body.htm (accessed March 9, 2017)

Fowler, A. E., Leffler, J. W., Johnson, S. P., Lawrence, B. D., and Sanger, D. M. (2018). Relationships between meteorological and water quality variables and fisheries-independent white shrimp (Litopenaeus setiferus) Catch in the ACE Basin NERR, South Carolina. Estuar. Coasts. 41:79. doi: 10.1007/s12237-0160171-4

Gell, F. R., and Roberts, C. M. (2002). The Fishery Effects of Marine Reserves and Fishery Closures. Washington, DC: WWF.

Gilbert, D. J. (1997). Towards a new recruitment paradigm for fish stocks. Can. J. Fish. Aquat. Sci. 54, 969-977. doi: 10.1139/f96-272 
Grüss, A., Kaplan, D. M. M., and Robinson, J. (2014a). Evaluation of the effectiveness of marine reserves for transient spawning aggregations in datalimited situations. ICES J. Mar. Sci. 71, 435-449. doi: 10.1093/icesjms/fst028

Grüss, A., and Robinson, J. (2015). Fish populations forming transient spawning aggregations: should spawners always be the targets of spatial protection efforts? ICES J. Mar. Sci. 69, 1205-1217.

Grüss, A., Robinson, J., Heppell, S. S., Heppell, S. A., and Semmens, B. X. (2014b). Conservation and fisheries effects of spawning aggregation marine protected areas: what we know, where we should go, and what we need to get there. ICES J. Mar. Sci. 71, 1515-1534. doi: 10.1093/icesjms/fsu038

Guanco, M. R., Mesa, S. V., Belga, P. B., and Nuñal, D. P. M. (2009). Assessment of the Commercial Fisheries of Western and Central Visayan Sea. Iloilo City: National Stock Assessment Project Bureau of Fisheries and Aquatic Resources, 45.

Horwood, J. W. (2000). "No-take zones: a management context," in Effects of Fishing on Non-Target Species and Habitats: Biological, Conservation and SocioEconomic Issues, eds M. J. Kaiser and S. J. De Groot (Oxford: Blackwell Science), 302-312.

International Fisheries Commission (IFC) (1948). Regulation and Investigation of the Pacific Halibut Fishery in 1947. Rep.Int.Fish.Comm. Washington, D.C: IFC, 35.

Jiang, Y.-Z., Cheng, J.-H., and Li, S.-F. (2009). Temporal changes in the fish community resulting from a summer fishing moratorium in the northern East China Sea. Mar. Ecol. Prog. Ser. 387, 256-273. doi: 10.3354/meps08078

Kanamori, Y., Takasuka, A., Nishijima, S., and Okamura, H. (2019). Climate change shifts the spawning ground northward and extends the spawning period of chub mackerel in the western North Pacific. Mar. Ecol. Prog. Ser. 624, 155-166. doi: $10.3354 /$ meps 13037

Kawasaki, T., and Omori, M. (1988). "Fluctuations in the three major sardine stocks in the Pacific and the global trend in temperature," in Long-Term Changes in Marine Fish Populations, eds T. Wyatt and M. G. Larrañeta (Vigo, Spain: Instituto de Investigaciones Marinas de Vigo), 37-53.

Kawasaki, T., Tanaka, S., Toba, Y., and Taniguchi, A Eds (1991). Long-Term Variability of Pelagic Fish Population and Their Environmental. Tokyo: Pergamon Press, 402.

Kurota, H., Szuwalski, C. S., and Ichinokawa, M. (2020). Drivers of recruitment dynamics in Japanese major fisheries resources: effects of environmental conditions and spawner abundance. Fish. Res. 221:105353. doi: 10.1016/j.fishres. 2019.105353

Liang, K.-Y., and Zeger, S. L. (1986). Longitudinal data analysis using generalized linear models. Biometrika 73, 13-22. doi: 10.1093/biomet/ 73.1.13

Lilly, G. R., Nakken, O., and Brattey, J. (2013). A review of the contributions of fisheries and climate variability to contrasting dynamics in two Arcto-boreal Atlantic cod (Gadus morhua) stocks: persistent high productivity in the Barents Sea and collapse on the Newfoundland and Labrador Shelf. Prog. Oceanogr. 114, 106-125. doi: 10.1016/j.pocean.2013.05.008

Lluch-Belda, D., Crawford, R. M. J., Kawasaki, T., MacCall, A. D., Parrish, R. H., Schwartzlose, R. A., et al. (1989). World-wide fluctuations of sardine and anchovy stocks: the regime problem. S. Afr. J. Mar. Sci. 8, 195-205. doi: 10.2989/02577618909504561

Lluch-Cota, D. B., Hernández-Vázquez, S., and Lluch-Cota, S. E. (1997). Empirical Investigation on the Relationship Between Climate and Small Pelagic Global Regimes and El Niño-Southern Oscillation (ENSO). FAO Fisheries Circular. No: 934 1997. Rome: FAO, 48.

MacKenzie, B. R., Bager, M., Ojaveer, H., Awebro, K., Heino, U., Holm, P., et al. (2007). Multi-decadal scale variability in the eastern Baltic cod fishery $1550-$ 1860-Evidence and causes. Fish. Res. 87, 106-119. doi: 10.1016/j.fishres.2007. 07.003

Mantua, J. M., and Hare, S. R. (2002). The pacific decadal oscillation. J. Oceanogr. $58,35-44$.

McClanahan, T. (2010). Effects of fisheries closures and gear restrictions on fishing income in a Kenyan Coral Reef. Conserv. Biol. 24, 1519-1528. doi: 10.1111/j. 1523-1739.2010.01530.x

Mendoça, J. T., and Sobrinho, R. P. (2013). Management of fishing of the Broadband Anchovy (Anchoviella lepidenstole) (Fowler, 1911), in south São Paulo State. Braz. Braz. J. Biol 73, 691-697. doi: 10.1590/s151969842013000400003
Mesa, S. V. (2014). The Fisheries Resource Status of Visayan Sea. Available online at: http://fscluster.org/sites/default/files/documents/BFAR\%20VI_Visayan\% 20Sea\%20Assessment\%20Report_050314.pdf (accessed January 16, 2018).

Muallil, R. N., Cabral, R., Mamauag, S., and Aliño, P. (2012). "Status, trend and sustainability of small-scale fisheries in the Philippines," in Proceedings of the 12th International Coral Reef Symposium, (Cairns, Aus).

Muallil, R. N., Cleland, D., and Aliño, P. M. (2013). Socio-economic factors associated with fishing pressure in small-scale fisheries along the West Philippine Sea biogeographic region. Ocean Coast. Manag. 82, 27-33. doi: 10.1016/j.ocecoaman.2013.04.013

Murawski, S. A., Brown, R., Lai, H.-L., Rago, P. J., and Hedrickson, L. (2000). Largescale closed areas as a fishery-management tool in temperate marine systems: the Georges Bank experience. Bull. Mar. Sci. 66, 775-798.

Napata, R. N., Espectato, L. N., and Serofia, G. D. (2020). Closed season policy in Visayan Sea, Philippines: a second look. Ocean Coast. Manag. 187:105115. doi: 10.1016/j.ocecoaman.2020.105115

National Oceanic and Atmospheric Administration (NOAA) (1985). Management of the shrimp fishery of the gulf of Mexico. In: FAO, Papers Presented at the Expert Consultation on the regulation of fishing effort (fishing mortality). Rome, 17-26 January 1983. A preparatory meeting for the FAO World Conference on fisheries management and development. FAO Fish. Rep, Vol. Suppl. 3. Washington, D.C: NOAA, 215-470.

Ojeda-Martinez, C., Bayle-Sempere, J. T., Sanchez-Jerez, P., Salas, F., Stobart, B., Goni, R., et al. (2011). Review of the effects of protection in marine protected areas: current knowledge and gaps. Animal Biodiversity and Conservation 34, 191-203.

Osenberg, C. W., Shima, J. S., Miller, S. L., and Stier, A. C. (2011). “Assessing effects of marine protected areas: confounding in space and possible solutions," in Marine Protected Areas. A Multidisciplinary Approach, ed. J. Claudet (Cambridge MA: Cambridge University Press), 143-167. doi: 10.1017/ cbo9781139049382.010

Overholtz, W. J., Hare, J. A., and Keith, C. M. (2011). Impacts of interannual environmental forcing and climate change on the distribution of Atlantic mackerel on the US Northeast continental shelf. Mar. Coast. Fish. 3, 219-232. doi: 10.1080/19425120.2011.578485

Pennsylvania State University (PSU) (2018). Introduction to Generalized Estimating Equations. Available online at: https://newonlinecourses.science.psu. edu/stat504/node/180/ (accessed December 15, 2019).

Philippine Statistics Authority (PSA) (2016). Highlights of the Philippine Population 2015 Census of Population. Available online at: https://psa.gov.ph/content/ highlights-philippine-population-2015-census-population (accessed March 19, 2021).

Philippine Statistics Authority (PSA) (2018). Fisheries Production Data From 2007-2018. Available online at: http://openstat.psa.gov.ph/ (accessed August 1, 2018).

Ramos, G. (2014). Oceana Philippines supports closed fishing season in Visayan Sea. Available online at: http://ph.oceana.org/press-releases/oceana-philippinessupports-closed-fishing-season-visayan-sea (accessed February 1, 2018).

Republic Act (RA) 8550 (1998). The Philippine Fisheries Code of 1998. Available online at: http://www.lawphil.net/statutes/repacts/ra1998/ra_8550_1998.html (accessed September 12, 2016).

Rokicki, S., Cohen, J., Fink, G., Salomon, J. A., and Landrum, M. B. (2018). Inference with difference-in-differences with a small number of groups. Med. Care 56, 97-105. doi: 10.1097/mlr.0000000000000830

Rola, A. C., Narvaez, T. A., Naguit, M. R. A., Elazeguia, D. D., Brillo, B. B. C., Paunlaguia, M. M., et al. (2018). Impact of the closed fishing season policy for sardines in Zamboanga Peninsula. Philippines. Mar. Policy 87, 40-50. doi: 10.1016/j.marpol.2017.09.029

Ronquillo, I. A., and Llana, M. E. G. (1987). "Biological effects of fishery management measures in the Philippines," in A Paper Presented during the Symposium on the Exploitation and Management of Marine Fishery Resources in Southeast Asia, 16-19 Feb 1987, (Australia), 244-248.

Sadovy, Y., and Domeier, M. (2005). Are aggregation-fisheries sustainable? Reef fish fisheries as a case study. Coral Reefs 24, 254-262. doi: 10.1007/s00338-0050474-6

Sanchirico, J. N. (2005). Additivity properties in metapopulation models: implications for the assessment of marine reserves. J. Environ. Econ. Manag. 49, 1-25. doi: 10.1016/j.jeem.2004.03.007 
Sanchirico, J. N., and Wilen, J. E. (2001). A bioeconomic model of marine reserve creation. J. Environ. Econ. Manag. 42, 257-276. doi: 10.1006/jeem.2000.1162

Sinclair, M., and Valdimarsson, G. (2003). Responsible Fisheries in the Marine Ecosystem. Rome: FAO, 426.

Skern-Mauritzen, M., Ottersen, G., Handegard, N. O., Huse, G., Dingsør, G. E., Stenseth, N. C., et al. (2015). Ecosystem processes are rarely included in tactical fisheries management. Fish Fish. 17, 165-175. doi: 10.1111/faf.12111

Skud, B. E. (1985). "The history and evaluation of closure regulations in the pacific halibut fishery," in FAO, 1985 Papers Presented at the Expert Consultation on the Regulation of Fishing Effort (Fishing Mortality). Rome, 17-26 January 1983. A Preparatory Meeting for the FAO World Conference on Fisheries Management and Development. FAO Fish.Rep, Vol. Suppl.3, (Rome: FAO), 215-470.

Smith, E. P. (2002). "BACI design," in Encyclopedia of Environmetrics, Vol. 1, eds A. H. ElShaarawi and W. W. Piegorsch (Chichester: John Wiley \& Sons, Ltd), 141-148.

Spijkers, J., and Boonstra, W. J. (2017). Environmental change and social conflict: the northeast Atlantic mackerel dispute. Regional Environ. Chang. 17, 18351851. doi: 10.1007/s10113-017-1150-4

Subong, E. S. (2017). Visayan Sea 'Closed Season' for Herrings, Sardines, Mackerels. Available online at: https://pia.gov.ph/news/articles/1001808 (accessed February 10, 2020).

Stige, L. C., Rogers, L. A., Neuheimer, A. B., Hunsicker, M. E., Yaragina, N. A., Ottersen, G., et al. (2019). Density- and size-dependent mortality in fish early life stages. Fish Fish. 20, 962-976. doi: 10.1111/faf.12391

Thompson, E. F., and Freeman, N. L. (1930). History of the Pacific Halibut Fishery. Report Of The International Fisheriescommission, 5. Vancouver, BC. 61.
United Nations (2020). Progress Towards the Sustainable Development Goals, Report of the Secretary-General. New York NY: United Nations.

Vert-pre, K. A., Amoroso, R. O., Jensen, O. P., and Hilborn, R. (2013). Frequency and intensity of productivity regime shifts in marine fish stocks. Proc. Natl. Acad. Sci.U.S.A. 110, 1779-1784. doi: 10.1073/pnas.1214879110

Wang, Y., Duan, L., Li, S., Zeng, Z., and Failler, P. (2015). Modeling the effect of the seasonal fishing moratorium on the Pearl Estuary using ecosystem simulation. Ecol. Modell. 312, 406-416. doi: 10.1016/j.ecolmodel.2015.06.011

Willette, D. A., Bognot, E. D. C., Mutia, M. T. M., and Santos, M. D. (2011). Biology and Ecology of Sardines in the Philippines: A Review. Bureau of Fisheries and Aquatic Resources-National Fisheries Research and Development Institute, Technical Paper Series, August 2011, Vol. 13. Iloilo City: Bureau of Fisheries and Aquatic Resources-National Fisheries Research and Development Institute, 1.

Wilson, J. R., and Lorenz, K. A. (2015). "Generalized estimating equations logistic regression," in Modeling Binary Correlated Responses using SAS, SPSS and R. ICSA Book Series in Statistics, Vol. 9, (Cham: Springer).

Conflict of Interest: The authors declare that the research was conducted in the absence of any commercial or financial relationships that could be construed as a potential conflict of interest.

Copyright (c) 2021 Bagsit, Frimpong, Asch and Monteclaro. This is an open-access article distributed under the terms of the Creative Commons Attribution License (CC BY). The use, distribution or reproduction in other forums is permitted, provided the original author(s) and the copyright owner(s) are credited and that the original publication in this journal is cited, in accordance with accepted academic practice. No use, distribution or reproduction is permitted which does not comply with these terms. 